Manuscript Number:

Title: Local Impact of Humidification on Degradation in Polymer Electrolyte Fuel Cells

Article Type: Research Paper

Keywords: PEFC; water Management; Degradation; local measurements; current density distributions

Corresponding Author: Dr. daniel G Sanchez, Ph.D

Corresponding Author's Institution: Deutsches Zentrum für Luft- und Raumfahrt (DLR)

First Author: daniel G Sanchez, Ph.D

Order of Authors: daniel G Sanchez, Ph.D; Tiziana Ruiu; Indro Biswasa; Mathias Schulze; Stefan Helmly; K A Friedrich

Manuscript Region of Origin: GERMANY

Abstract: Water management represents one of the main challenges in the design and operation of Polymer Electrolyte Fuel Cells (PEFCs). Besides performance, the water level also affects the durability of the cell. Understanding the degradation processes is of vital importance for extending durability of PEFCs by suitable mitigation strategies. In this work, the degradation processes related to operation with fully- and nonhumidified gas streams were locally studied. The differences were analyzed using in-situ diagnostic tools, such as segmented cell for local current density measurements, during a $300 \mathrm{~h}$ test operating under constant conditions, in combination with local post-test analysis, i.e. SEM/EDX and XPS. The results showed the deep impact of the RH on homogeneity during the degradation process due to the fact that different water distribution influences the chemical environment. Under nonhumidified gas streams, the cathode inlet region exhibited increased degradation, whereas with fully humidified gases the bottom of the cell had the higher performance losses. The degradation and the degree of reversibility produced by Pt dissolution, PTFE defluorination, and contaminants such as silicon (Si) and nickel (Ni) were locally evaluated. 
January, 19, 2016

Dear Editor in chief of Journal of Power Sources,

We are pleased to submit the manuscript entitled" Local Impact of Humidification on Degradation in Polymer Electrolyte Fuel Cells ", under consideration for publication in the Journal of Power Sources.

The corresponding author of this manuscript is Dr. Daniel G.Sanchez and the co-authors are Dr. Tiziana Ruiu, Dr. Indro Biswas, Dr. Mathias Schulze, Dr. Stefan Helmly and Prof. Dr. K. Andreas Friedrich.

This manuscript presents a study of the degradation processes related to operation with fully- and non-humidified gas streams. The differences were analyzed using in-situ diagnostic tools, such as segmented cell for local current density measurement . The results showed the deep impact of the $\mathrm{RH}$ on homogeneity during the degradation process due to the fact that different water distribution influences the chemical environment.

We believe our findings related to the the degradation and the degree of reversibility produced by $\mathrm{Pt}$ dissolution, PTFE defluorination, and contaminants such as silicon ( $\mathrm{Si}$ ) and nickel (Ni) can be of high interest for the PEMFC research community.

Please address all correspondence concerning this manuscript to me and feel free to correspond with me by e-mail.

With the submission of this manuscript we affirm that the above mentioned manuscript consists of original, unpublished work and it has not been submitted to any other journal for reviews.

Sincerely,

Daniel G. Sanchez 


\section{Highlights}

- Locally resolved current density measurements reveal high localized degradation

- Contaminants such as Ni and Si induce local degradation

- Ni contamination leads to irreversible degradation, Si produces recoverable loses

- Identification of Ni contamination as a RH dependent degradation agent

- Defluorination of the ionomer is observed under full humidity conditions 


\title{
Local Impact of Humidification on Degradation in Polymer Electrolyte Fuel Cells
}

\author{
Daniel. G. Sanchez*a ${ }^{\mathrm{a}}$, Tiziana Ruiu ${ }^{\mathrm{a}}$, Indro Biswas ${ }^{\mathrm{a}}$, Mathias Schulze ${ }^{\mathrm{a}}$, Stefan Helmly ${ }^{\mathrm{a}}$, \\ K. Andreas Friedrich ${ }^{\mathrm{a}}$ \\ ${ }^{a}$ Deutsches Zentrum für Luft- und Raumfahrt (DLR), Institut für Technische \\ Thermodynamik, 70569 Stuttgart, Germany
}

*Corresponding author:

Tel.: +49 71168628071 ; fax: +49 7116862322

E-mail: Daniel.GarciaSanchez@dlr.de (Daniel. G. Sánchez) 
Water management represents one of the main challenges in the design and operation of Polymer Electrolyte Fuel Cells (PEFCs). Besides performance, the water level also affects the durability of the cell. Understanding the degradation processes is of vital importance for extending durability of PEFCs by suitable mitigation strategies. In this work, the degradation processes related to operation with fully- and non-humidified gas streams were locally studied. The differences were analyzed using in-situ diagnostic tools, such as segmented cell for local current density measurements, during a $300 \mathrm{~h}$ test operating under constant conditions, in combination with local post-test analysis, i.e. SEM/EDX and XPS. The results showed the deep impact of the RH on homogeneity during the degradation process due to the fact that different water distribution influences the chemical environment. Under non-humidified gas streams, the cathode inlet region exhibited increased degradation, whereas with fully humidified gases the bottom of the cell had the higher performance losses. The degradation and the degree of reversibility produced by Pt dissolution, PTFE defluorination, and contaminants such as silicon ( $\mathrm{Si}$ ) and nickel (Ni) were locally evaluated.

KEYWORDS: PEFC, water management, degradation, local measurements, current density distributions. 
In recent years, significant progress has been made towards meeting the challenging cost, durability, and performance targets required for the use of PEMFCs in automotive applications announced by the U. S. Department of Energy. However, the currently achievable operation hours of $3900 \mathrm{~h} \mathrm{[1]} \mathrm{are} \mathrm{still} \mathrm{not} \mathrm{matching} \mathrm{the} 5000 \mathrm{~h}$ target for 2020 [2]. In order to reach the durability goals, degradation of cell components has to be understood and mitigated. To increase cell performance, activation losses, ohmic losses, and mass transfer losses have to be reduced. A factor that affects all of these aspects is the water content in the cell, which is governed by water formation, reactant humidification, and water transport.

The strong impact of the water on cell performance is caused by the water-dependent proton conductivity of perfluorosulfonic acid (PFSA) membranes, which is the state-ofthe-art ionomer used as membranes and in electrodes of PEMFCs. Its proton conductivity increases with the hydration level of the ionomer. Most likely, this is also the reason why oxygen reduction reaction (ORR) kinetics are reduced at low relative humidification (RH) [3]. Performance is, however, not only diminished by insufficient humidification but also by excessive water in the cell components responsible for gas transport. Condensation of water within the PEMFC, is likely to produce accumulation of liquid water in the porous electrodes and gas diffusion media (effect known as flooding), thus hindering the transport of reactants.

Since the possibility of simplifying the system by avoiding additional components is of great importance in the design of fuel cell systems for automotive application, operation with less or without humidification is preferred. Numerous studies have investigated the operation of PEMFC under dry conditions. Early work by Büchi et al. demonstrates stable performance for PEMFC using non-humidified or slightly humidified gases [4]. Strategies for operating PEMFCs include also the reduction of humidification of both reactant gases [5]-[7] or the dry operation of cathode [8]-[13] or anode sides [14].

Besides performance, the water level influences also the durability of the cell. Generally, studies report an increase of reactant crossover rate and voltage loss rate, as well as accumulation of structural membrane defects as consequences of operation at low RH [15]-[21]. However, different dependencies of durability on RH level were reported. On the one hand, a correlation between degradation and RH level was observed [22], on the other hand degradation was highest at medium RH values [23]. The authors interpreted this non-linearity as the result of the interaction of different $\mathrm{RH}$ effects on chemical membrane degradation [23]. In this chemical degradation mechanism, the reaction of hydrogen and oxygen diffusing through the membrane can lead to the formation of hydrogen peroxide $\left(\mathrm{H}_{2} \mathrm{O}_{2}\right)$, and in further consequence to the formation of radicals $(\mathrm{OH} \cdot)$, which decompose the membrane [24]. This mechanism is catalyzed by Pt [25]-[30] and metallic cations [24], [31], [32]. Thus, impurities from e.g. tubing or stack components 
such as $\mathrm{Cu}^{2+}$ or $\mathrm{Fe}^{2+}$, and $\mathrm{Pt}$ precipitates in the membrane resulting from catalyst dissolution can aggravate membrane degradation.

The level of RH generally influences the chemical degradation mechanism in multiple aspects. First, it influences the reactant crossover through the membrane, since membrane permeability increases with water content [33]-[35]. Second, it influences the rates of decomposition of the membrane by enhancing Pt dissolution and precipitation in the membrane. Furthermore, also reaction rates at $\mathrm{Pt} / \mathrm{Nafion}^{\circledR}{ }^{\circledR}$ interfaces are influenced because of its impact on the surface oxidation state of $\mathrm{Pt}$, on the permeation of reactants to the active sites and and on the proton activity of the ionomer phase. The influence of $\mathrm{RH}$ on Pt surface state arises out of the oxide layer formation on Pt from water (also possible from $\mathrm{O}_{2}$ gas) [36]-[38]. Because the oxide layer represents a protection from dissolution, RH affects the Pt stability [39]-[41]. The proton activity/conductivity of the ionomer phase influences the proton transfer in the ORR. Since the water content of the ionomer determines its proton activity, $\mathrm{RH}$ can affect the formation rate of water (two electrons ORR pathway) and $\mathrm{H}_{2} \mathrm{O}_{2}$ (four electron ORR pathway). Third, it influences (together with the gas flow rate) the water flux through the MEA and therefore the transport rate of contaminants, e.g. $\mathrm{Cu}^{2+}, \mathrm{Fe}^{2+}$ and $\mathrm{Pt}^{2+}[21]$.

The described effects differ in their dependence on $\mathrm{RH}$ as the maximum degradation at medium RH observed by Xu et al. indicates [23]. Following dependencies were observed: $\mathrm{Pt}$ dissolution was reported to decrease with increasing $\mathrm{RH}$ [42].Nevertheless, the precipitation of $\mathrm{Pt}$ in the membrane was found to be higher at high $\mathrm{RH}$ [43]. In contrast, Inaba et al. noticed an increase of $\mathrm{Fe}$ ion $\left(\mathrm{Fe}^{2+}\right.$ or $\left.\mathrm{Fe}^{3+}\right)$ concentration in the condensate water at high RH [21]. They concluded that impurities accumulate in the cell at low RH and are washed out at high level of humidification. Regarding the reactant crossover rate, the increase of $\mathrm{RH}$ should result in a higher degradation rate due to increased formation of $\mathrm{H}_{2} \mathrm{O}_{2}$ /radicals. However, the maximum rate of $\mathrm{H}_{2} \mathrm{O}_{2}$ formation was observed at medium RH, dropping at higher and lower RH [44]. This might be related to the impact of water content on ORR activity. It was discovered that the intrinsic ORR kinetics is independent of humidification at RH > 50-60\% but decreases clearly with RH below this value [3], [45].

Previous studies investigated the effect of humidification extensively and provided important insight. However, so far, little attention has been paid to the fact that the effect of water in the cell is a highly local effect, which demands appropriate tools to determine the causes for performance loss [6], [46]. Furthermore, the introduction of advanced membranes with improved mechanical properties, chemical resistance, and higher ionic conductivity at low RH by additives may change the reported dependencies. To our knowledge, the influence of RH on this kind of membrane has not been studied yet. To close these two gaps, we systematically investigated the impact of $\mathrm{RH}$ on performance, durability, and operational stability of MEAs equipped with a more recent membrane type. This work presents the comparative study of the local degradation caused by operation of a single cell at non-humidified and fully humidified gas supply.

\section{Experimental details}


The effect of relative humidification on the cell behavior was studied using $142 \mathrm{~cm}^{2}$ MEAs consisting of a commercial Nafion ${ }^{\circledR} \mathrm{XL}$ membrane coated with a Pt/C based catalyst layer, and with a Pt loading of $0.3 \mathrm{mg}_{\mathrm{P}_{t}} \mathrm{~cm}^{-2}$ on both sides (Ion Power Inc.). The catalyst coated membrane was placed between the gas diffusion layers Sigracet 25 BC (SGL Carbon SE). The end- and bipolar plates were provided with a multi-serpentine flow field (see Fig. 1). The end-plates were gold-coated and the bipolar plates were graphite-based. The gaskets used on anode and cathode side were manufactured from high temperature silicone with low Shore hardness (Eisenhuth GmbH \& Co. KG).. The operating conditions are summarized in Table 1. The cell was developed in-house to be used for in-stack testing at the German Aerospace Center (DLR) [47].

The test bench allowed automatic control of the operating cell conditions, such as cell pressure, cell temperature, gas flow rates, and humidity of reactants. The relative humidity of the inlet gases was controlled by mass evaporator mixers The reactant pressure was measured and controlled at the cell reactant outlet.

To investigate the $\mathrm{RH}$ influence on the cell behavior, the MEAs were operated galvanostatically at $100 \mathrm{~A}$ for more than $275 \mathrm{~h}$. The cell temperature was set to $60^{\circ} \mathrm{C}$. In the case of the MEA operated at wet conditions, water-saturated reactants were supplied to the cell; hence the RH was approx. $100 \%$. For the MEA operated at non-humidified conditions, the reactant flows bypassed the humidifiers; in this case, the RH was approx. $5 \%$, since the incoming gases from the pipeline are at ambient temperature, therefore a residual humidity is present. In both cases, the reactants were supplied to the cell with a flow rate of $840 \mathrm{ml} \mathrm{min}^{-1}$ for hydrogen and $3320 \mathrm{ml} \mathrm{min}^{-1}$ for air, both at a pressure of 1.5 bar. Before and after the test, the cells were electrochemically characterized using E-j curves and cyclic voltamogramms (CVs). The measurement time is hereafter referred to as begin of test (BoT) and end of test (EoT), respectively. It has to be noted that, for both MEAs, during the BoT and EoT characterization the temperature was set to $80^{\circ} \mathrm{C}$, and the reactant humidification was kept at $100 \% \mathrm{RH}$ for the cyclic voltammetry measurements and $50 \% \mathrm{RH}$ for the E-j curves. The operating conditions are summarized in Table 1.

\section{Table 1}

Operating conditions and location of segments at anode/cathode inlet and outlet.

\begin{tabular}{ll}
\hline Cell Temperature & $60{ }^{\circ} \mathrm{C}$ (durability test) \\
& $80{ }^{\circ} \mathrm{C}$ (characterization) \\
Reactant pressure & $1.5 \mathrm{bar}$ \\
Total current & $100 \mathrm{~A}$, i.e. $0.7 \mathrm{~A} \mathrm{~cm}^{-2}$ (durability test) \\
Gas flow rate & Anode $\left(\mathrm{H}_{2}\right): 840 \mathrm{ml} \mathrm{min}^{-1}$ \\
& Cathode $\left(\right.$ Air): $3320 \mathrm{ml} \mathrm{min}^{-1}$ \\
Relative humidity & $5 \% / 5 \%$ or $100 \% / 100 \%$ (durability test) \\
& $50 \% / 50 \%$ (characterization) \\
Segments location & Anode inlet: A1, B1, C1 \\
& Anode outlet: G10, H10, I10 \\
& Cathode inlet: G1, H1, I1 \\
& Cathode outlet: A10, B10, C10
\end{tabular}


Performance losses were compared by means of current densities, E-j curves and ECSA (electrochemically active surface area) at the beginning and at the end of the test. In order to investigate degradation, the chemical composition of the MEA was locally examined post-mortem with SEM/EDX and XPS.

To visualize the effects of different relative humidity levels on the homogeneity of the current distribution, locally resolved current density measurements were performed, using a segmented bipolar plate as anode plate. For that purpose, the DLR patented printed circuit board (PCB) [48] was adapted to a segmented bipolar plate with $142 \mathrm{~cm}^{2}$ active surface divided into 90 segments. Fig. 1 shows the multi-serpentine segmented bipolar plate design used in the present experiments, indicating the location of the cell segments in a) anode side and b) cathode side flow fields, as well as c) the color legend for the current density values.

Cyclic voltammograms (CVs) were recorded to determinate the ECSA using the electrochemical station IM6 in combination with the power potentiostat PP241 Thales Z1.21 USB software (Zahner-Elektrik $\mathrm{GmbH} \& \mathrm{Co}$. KG). The CVs were performed at ambient pressure ( 1 bar) and $80{ }^{\circ} \mathrm{C}$, using water-saturated gases $(100 \% \mathrm{RH})$.

\subsection{Current - voltage curve measurement}

To evaluate the power losses which occurred after the durability test and the reversibility of the degradation, current - voltage curves [E-j] were measured under conditions that enhance the cell recovery for both experiments. Hence, the E-j curves were performed in galvanostatic mode at a cell temperature of $80{ }^{\circ} \mathrm{C}$ while the reactant humidification was set at $50 \% \mathrm{RH}$, in order to adopt an intermediate value between the two experiments. The reactant flow rates were maintained constant, as reported in Table 1. Each operation point was held for at least 5 minutes.

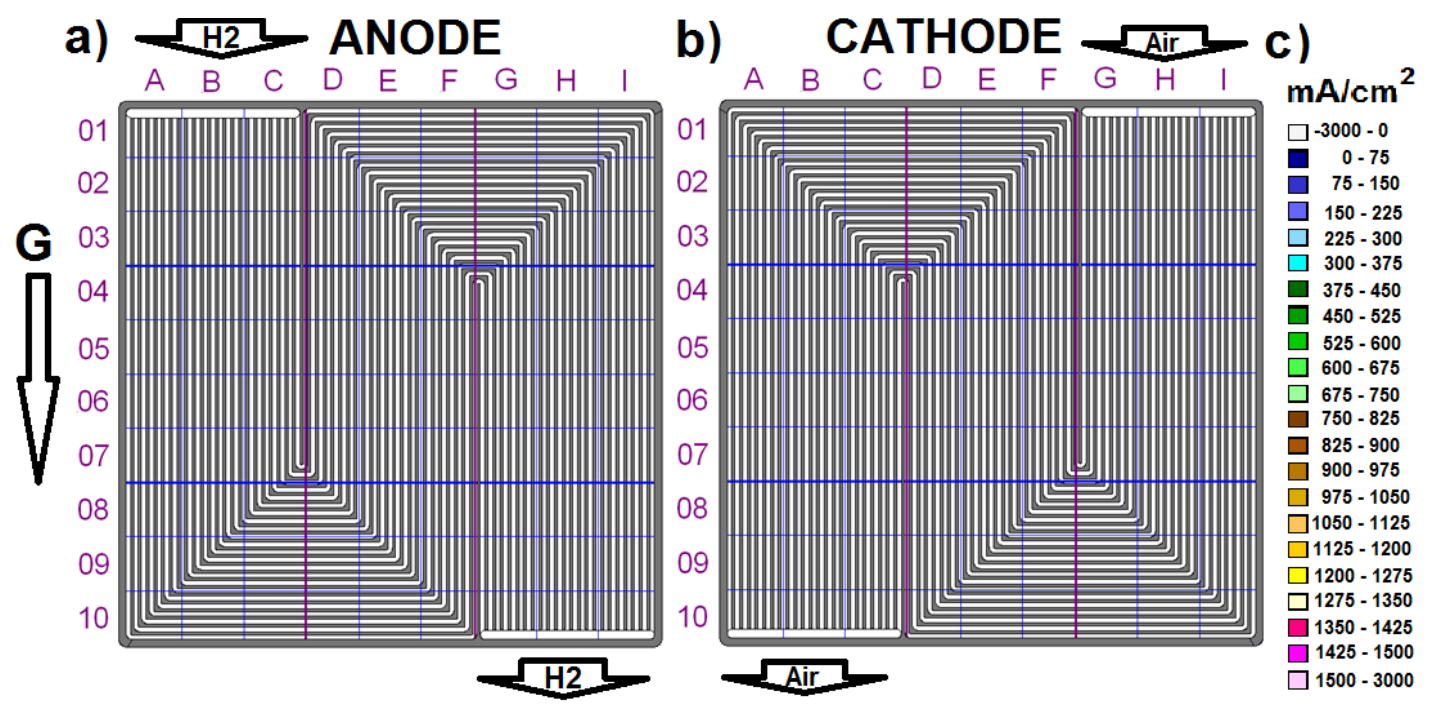

Fig. 1. Multi-serpentine segmented cell design: segment distributions at the (a) anode and (b) cathode side, with (c) color code for current density values ranges. The $\mathrm{G}$ arrow represents the position of the cell in the gravitational field. 


\subsection{XPS}

Photoemission spectra were recorded using a hemispherical analyser in an ultrahigh vacuum chamber of a base pressure of $4 \cdot 10^{-10}$ mbar (Thermo Scientific ESCALAB250). Electrons were emitted using a standard Al Ka source (Thermo Scientific XR4, 300 W). Applying a small spot lens mode, high resolution spectra were recorded from a sampled spot size of $\sim 200 \mu \mathrm{m}$ with an energy resolution of $\sim 0.5 \mathrm{eV}$. Absolute energy scales were calibrated by referencing the $\mathrm{Ag} 3 \mathrm{~d}$ signals of a cleaned contaminant free silver surface. Samples of approximately $5 \mathrm{~mm}$ in width were cut from selected positions and the gas diffusion layer (GDL) was delaminated by hand from the active layer to access the interface between catalyst layer (CL) and microporous layer (MPL) in addition to the GDL backing surface. Only samples with no apparent material transfer from the detached component were analyzed.

Nickel 2p spectra were cross-checked with an $\mathrm{Mg} \mathrm{K \alpha}$ source (Thermo Scientific XR4, $300 \mathrm{~W}$ ) in order to separate the signals from the abundant Auger signals of the present fluorine atoms. The information depth is approximately 10 nanometres.

\subsection{SEM/EDX}

SEM and EDX were used to examine CCM cross-sections from selected segments regarding membrane thinning and chemical composition. Samples with a width (i.e., cross-sectional length) of approximately $3 \mathrm{~mm}$ were cut from the MEAs at the selected segments after operation in the test station. In addition, a reference sample was taken from a pristine MEA. Cross-sections were prepared via freeze-fractioning. For this, GDLs were removed from the samples, which were then immersed in liquid nitrogen and broken. SEM and EDX measurements were conducted on an ULTRA plus (Zeiss Corp.) scanning electron microscope. The resolution of the SEM was $1.0 \mathrm{~nm}$ at $15 \mathrm{kV}$ and $1.7 \mathrm{~nm}$ at $1 \mathrm{kV}$. Images were recorded based on secondary electrons and backscattered electrons at $5 \mathrm{kV}$. The SEM was equipped with an XFlash ${ }^{\circledR} 5010$ EDX detector (Bruker Corp.) with an energy resolution of $123 \mathrm{eV}$ at $\mathrm{Mn} \mathrm{K \alpha}$. The EDX measurements were performed for $150 \mathrm{~s}$ at $10 \mathrm{kV}$. Each cross section was investigated at three different positions. At each position, separate EDX area scans were recorded in anode, cathode and membrane layer. EDX spectra were quantitatively analyzed with the software Esprit 1.9 (Bruker Corp.). Furthermore, SEM images were used to determine the thicknesses of the membranes. The EDX information depth is about 2-3 $\mu \mathrm{m}$.

\section{Results}

This work investigates the influence of using extreme humidification conditions at the gas inlets on degradation. With this purpose, two opposite conditions were selected: first, supplying the cell with non-humidified gases (RH approx. $5 \%$, see Section 2 for details), and second, streaming the cell with fully humidified gases (water-saturated gases, RH approx. $100 \%$ ). 


\subsection{Operation under non-humidified gas supply}

With the aim of studying the local degradation processes associated to operation under low humidity gas supply, the MEA was operated with dry reactants for more than $275 \mathrm{~h}$ at constant current under the conditions described in Table 1. The evolution of the cell voltage suggests strong degradation. Two different slopes can be observed during the voltage drop, the steepest occurred during the first minutes $\left(26 \mathrm{mV} \mathrm{h}^{-1}\right)$, as is shown in Fig. 2a. This can be related to dehydratation of the ionomer, as is described in ref. [6], [46]. Nevertheless, after this initial stabilization a softer voltage drop was measured (146 $\mu \mathrm{V} \mathrm{h}^{-1}$ ) and the slope remained constant during the rest of the experiment.

The voltage drop was accompanied by a non-homogeneous current densities evolution, as displayed in Fig. 2b-d. The region at the cathode inlet (Fig. 1, columns G, H, and I) experienced a significant reduction on current density during the experiment due to the evaporation related membrane dehydration caused by the higher mass flow rate at the cathode, where the air stream was about four times larger than the hydrogen stream at the anode (see Table 1). This is consistent with the dominant influence of cathode RH on cell performance stability, as reported in [4], [6], [46].

a)
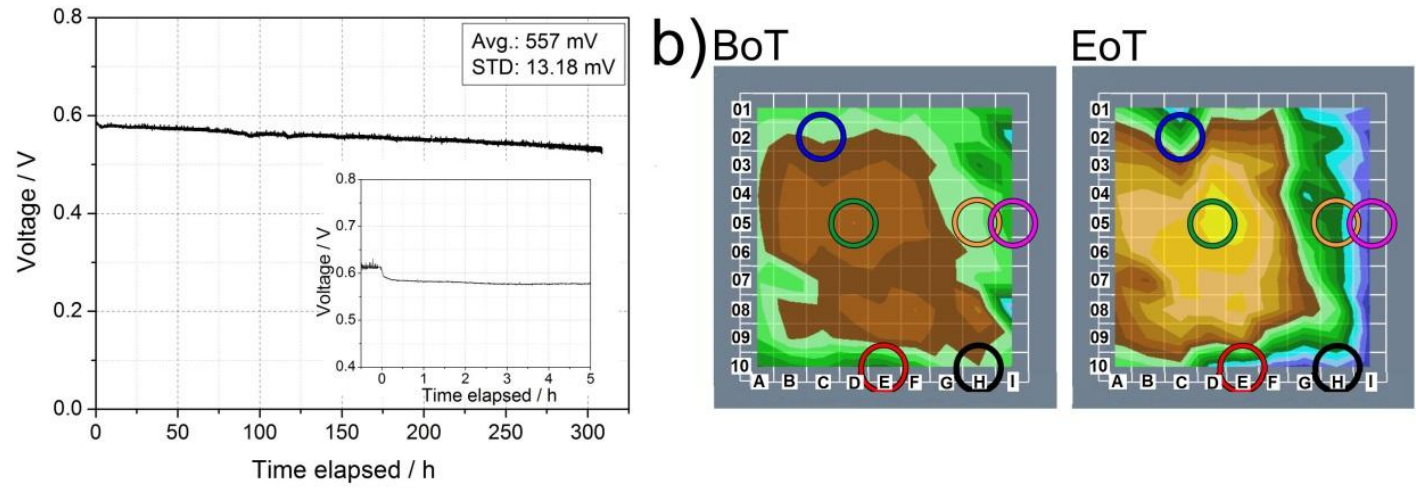

c)
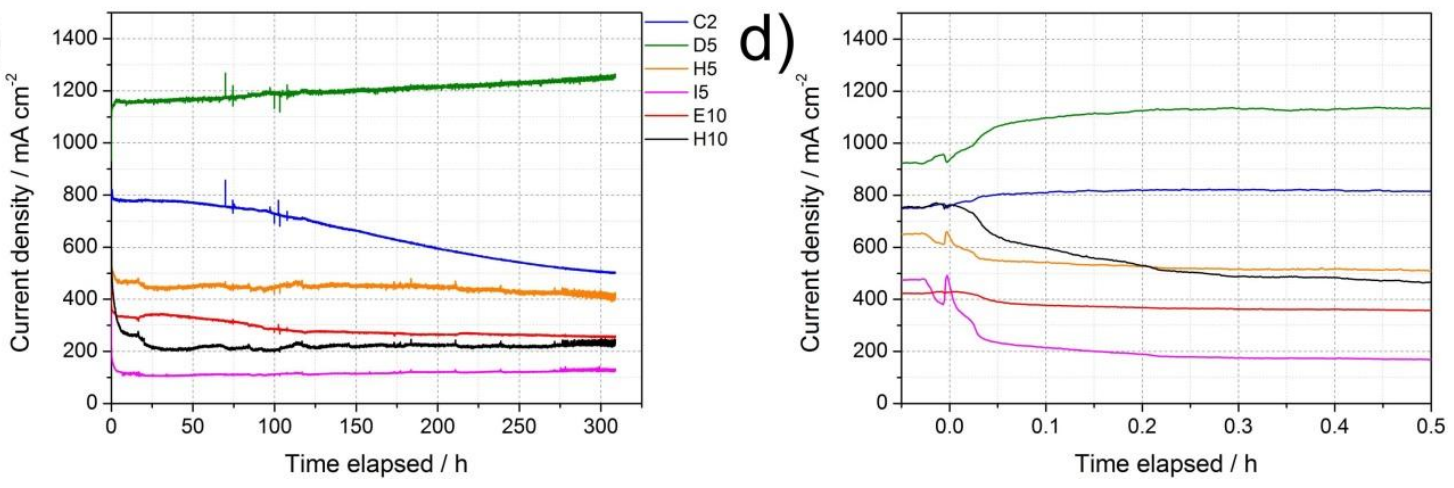

Fig. 2. Cell operation under non-humidified gas supply (approx. $5 \% \mathrm{RH}$ ). a) Development of cell voltage during the approx. $300 \mathrm{~h}$ long-term experiment at $0.7 \mathrm{~A} \mathrm{~cm}^{-2}$ and $60{ }^{\circ} \mathrm{C}$. The inset plot shows the voltage decay in the first $5 \mathrm{~h}$. At $0 \mathrm{~h}$, the gas humidification was switched off. b) Current density plots at BoT and EoT. The colored circles indicate the segments that underwent ex-situ analyses (see Section 3.1.1 and 3.1.2). c) Cell current density evolution during the long-term experiment and d) during the first $0.5 \mathrm{~h}$ for the segments analyzed ex-situ and displayed in b).

A closer examination of the local changes in current distribution is shown in Fig. $2 b$ and c. At the initial phase of the experiment (see Fig. 2d), it can be observed that the current 8 
had redistributed within the first $15 \mathrm{~min}$. The current declined mainly in the area of the cathode inlet (segments H5, I5, and H10) and rose in return in other areas, e.g. in C2 and D5, due to the necessary compensation of these losses (galvanostatic operation). This redistribution can be attributed to the equilibration of the current flow. As in the case explained before, the current had to increase simultaneously in a different area, in this case e.g. in D5.

The long-term operation under non-humidified gas supply affected especially the cathode (ECSA loss of $13.3 \%$ between BoT and EoT). The anode was less affected by the low humidity operation, as indicated by the lower ECSA loss of $6.9 \%$. (CVs see Fig. S1 in Supplementary Data).

\subsubsection{SEM/EDX}

To identify the causes of degradation, SEM and EDX were used to examine the chemical composition of selected areas of the CCM and to check for thinning of the membrane. The examined samples gave evidence for local contamination as the reason for performance degradation.

Before presenting the detailed results, it has to be noted that the used CCMs contained the Nafion ${ }^{\circledR}$ XL membrane which consists of three layers: two outer membrane layers sandwiching a PTFE-based reinforcement layer (see Fig. S2 in Supplementary Data). To distinguish between the two membrane layers, we will refer to them as anode-side and cathode-side membrane (An-M and Ca-M, respectively). Furthermore, Si based particles are visible in the two membrane layers. Most likely, they are $\mathrm{SiO}_{2}$ particles which are used for water retention in the membrane in order to improve its conductivity at low RH. This functionality was described in several studies [49]-[58].

The samples selected for analysis stemmed from the segments C2, D5, H5, I5, E10, and $\mathrm{H} 10$ (see colored circles in Fig. 2b for segment location). With EDX, traces of Ni (in membrane and electrodes), Si (in addition to membrane, also in electrodes) and Pt (in addition to electrodes, also in membrane) were detected, which were not present in the pristine CCM.

As can be seen from Table 2, significant $\mathrm{Ni}$ contamination of the electrode and membrane layers was detected in the segment at the anode inlet (C2) and at the bottom $180^{\circ}$ curve in the cathode flow field (E10). These two segments suffered from a distinct decrease in current density of $34 \%$ (C2) and $40 \%$ (E10) during the experiment. The Ni source was most likely in the coating of the steel end plates, since $\mathrm{Ni}$ was present as a sublayer under the gold surface layer on the coated plates. When inspecting the coating after the experiment, it was noticed that the gold layer had defects in the compartments of the gas inlet, which were accompanied by a local green coloring of the surface. Most likely, this was $\mathrm{NiO}$, which means that the Ni layer was indeed exposed. Therefore, it can be assumed that Ni ions were released and transported into the MEA.

\section{Table 2}

Result of the quantitatively analyzed EDX spectra for $\mathrm{Ni}, \mathrm{Si}$, and Pt in the MEA operated under nonhumidified gas supply. Given values are averaged from at least three measured values. An-M and Ca-M 9 
indicate analysis results of membrane samples at the anode and cathode side, respectively; PTFE indicates the membrane PTFE-reinforcement layer; An and Ca refer to analysis of anode and cathode catalyst layer, respectively.

\begin{tabular}{|c|c|c|c|c|c|c|c|c|c|c|c|}
\hline \multirow[b]{2}{*}{ Segment } & \multicolumn{5}{|c|}{$\mathrm{Ni} / w t \%$} & \multicolumn{5}{|c|}{$\mathrm{Si} / \mathrm{wt} \%$} & \multirow[b]{2}{*}{ PTFH } \\
\hline & An-M & PTFE & Ca-M & An & $\mathbf{C a}$ & An-M & PTFE & Ca-M & An & $\mathrm{Ca}$ & \\
\hline $\mathrm{C} 2$ & $3.4 \pm 2.9$ & $2.6 \pm 2.3$ & $3.6 \pm 3.2$ & - & $0.5 \pm 0.9$ & $2.3 \pm 0.7$ & $0.3 \pm 0.1$ & $1.5 \pm 0.7$ & $1.1 \pm 0.5$ & - & $0.4 \pm 0$ \\
\hline D5 & $0.1 \pm 0.1$ & $<0.1$ & $0.2 \pm 0.2$ & - & - & $2.2 \pm 0.5$ & $0.3 \pm 0.3$ & $1.4 \pm 0.6$ & - & $0.3 \pm 0.5$ & $0.7 \pm 0$ \\
\hline H5 & - & - & - & - & - & $0.6 \pm 0.2$ & $0.1 \pm 0.1$ & $0.7 \pm 0.2$ & - & $0.5 \pm 0.2$ & $<0.1$ \\
\hline I5 & - & $0.2 \pm 0.2$ & $<0.1$ & - & - & $3.2 \pm 0.6$ & $<0.1$ & $2.3 \pm 0.5$ & $1.4 \pm 0.8$ & $1.2 \pm 0.6$ & - \\
\hline E10 & $2.9 \pm 0.4$ & $1.8 \pm 0.9$ & $2.8 \pm 0.3$ & $0.5 \pm 0.2$ & $0.2 \pm 0.2$ & $2.7 \pm 0.6$ & $0.2 \pm 0.1$ & $2.6 \pm 0.0$ & $0.8 \pm 0.4$ & $1.9 \pm 0.3$ & - \\
\hline H10 & - & - & - & - & - & $2.4 \pm 0.5$ & $0.3 \pm 0.3$ & $1.9 \pm 0.2$ & $1.2 \pm 1.1$ & $2.4 \pm 1.3$ & $0.1 \pm 0$ \\
\hline Pristine MEA & - & - & - & - & - & $2.0 \pm 0.7$ & $0.1 \pm 0.1$ & $1.5 \pm 0.6$ & - & - & - \\
\hline
\end{tabular}

In the case of $\mathrm{Si}$ in the CCM, the findings listed in Table 2 imply a contamination of the electrodes (not of the membrane, since the membrane contains Si particles, as mentioned above). Possible sources are the membrane and the silicone sealing. [59], [60] The latter was checked for by examining an operated MEA which does not contain $\mathrm{Si}$ in the membrane or electrodes, but which was equipped with the same silicone sealing. In this MEA, after operation, Si was present in the electrodes but not in the membrane. A further aspect indicating that the sealing was the Si source is the fact that Si contamination of the Ion Power MEAs was higher in the segments directly next to the gaskets (I5, E10, H10). From this, we conclude that the observed $\mathrm{Si}$ in the electrodes originated mainly from the sealing which underwent decomposition.

Tan et al. reported that silicone degrades via de-crosslinking and chain scissoring in the rubber backbone [61], [62]. Bhargava et al. postulated that silicone is leaching siloxane species which can react with fuel cell reactants to silicic acid. In a further reaction, Si in the silicic acid can exchange into the PFSA membrane[63]. However, the authors analyzed the level of Si contamination for the whole MEA, not only for the membrane. Therefore, it cannot be concluded from their results that Si was intruding into the bulk membrane. In our experiment, the Si content is higher in all analyzed segments than in the pristine membrane (see Table 2), except in H5. Furthermore, the segments with Si in both electrodes (I5, E10 and H10) have also the highest Si content in the membrane layers; nevertheless, the standard deviation of the $\mathrm{Si}$ content is generally too high to clearly identify a trend. When further taking into account that $\mathrm{Si}$ was not detected in the membrane of the MEA that was free of $\mathrm{SiO}_{2}$ particles, it can be concluded that, in our experiment, Si was mainly accumulating in the electrodes. This seems plausible because the electrodes have a higher porosity and consequently a higher permeability than the membrane.

Another contaminant present in the membrane was Pt (see Table 2). Although only traces of it were detected by EDX, micrographs clearly showed metallic Pt particles in the cathode-side membrane and the PTFE layer (see Fig. S3 in the Supplementary Data). The Pt precipitates are known to catalyze chemical decomposition in the membrane, resulting in membrane thinning. However, the measured thickness values of the operated membrane were between 24 and $28 \mu \mathrm{m}$, and did not differ strongly from the thickness of 
the pristine membrane of approx. $26 \mu \mathrm{m}$. Therefore, membrane decomposition was obviously not an issue.

\subsubsection{X-ray photoelectron spectroscopic studies (XPS)}

The degradation of the fluorinated ionomer and of the PTFE additive in MPL and GDL, respectively, was also characterized with X-ray photoemission spectroscopy [64].

Samples were taken from selected segments of the MEA after operation (sample denotation according to the PCB segmentation depicted in Fig. 1). Carbon spectra of the delaminated CLs of segments D5 and I5, as samples for the central and the more degraded edge area of the cell (see Fig. 1 and 2 for positions) is displayed in Fig. 3a and b. The carbon 1s signal is comprised of two basic signals for this kind of samples. The signal at 284-285 eV (labelled $\mathrm{C}=\mathrm{C}$ ) represents graphitic carbon, or carbon fibers of the GDL backing, or hydrocarbons without heteroatoms. The signal at 291-292 eV represents fluorinated compounds, i.e. the ionomer, or PTFE in MPL and GDL backing (labelled C$F_{2}$ ). The polarized chemical bonding of carbon atoms to fluorine, with its higher electronegativity, leads to a diminished local electron density at the carbon site, which is visible as a higher binding energy of the emitted electrons. It may have a shoulder to the high energy side, or even separated satellite signals in GDL backing (compare to Fig. 5), in particular when containing PTFE with its very weak electrical conductivity. Emerging broad signals in the range above $292 \mathrm{eV}$ are an indicator for agglomeration of poorly conductive material, i.e. the non-graphitic compounds, after local rearrangement or flaking from carbon fibres. Samples after operation, then, may exhibit a signal at $\sim 288 \mathrm{eV}$, which arises after partial defluorination (labelled $\mathrm{C}-\mathrm{F}_{1}$ ). The chemical bonding to one instead of two fluorine atoms leads to a higher local electron density at the site of carbon atom and an observed binding energy between the $\mathrm{C}=\mathrm{C}$ and the $\mathrm{C}-\mathrm{F}_{2}$ signals. The presence of oxygen bridges as outcome of the radical attack on the ionomer [26], similar to the well known structure of Fomblin $\mathrm{Y}^{\mathrm{TM}}$ [65], would yield an additional signal at $\sim 294 \mathrm{eV}$ and can not conclusively verified from the present data.

The carbon 1s signals of the anode CLs in Fig. 3.Error! Reference source not found. show little attributes of degradation in both displayed operated samples (segments D5 and I5). A small signal of defluorinated ionomer is visible in the valley between the $\mathrm{C}=\mathrm{C}$ and the $\mathrm{C}_{-} \mathrm{F}_{2}$ peaks. It is little more pronounced in the segment $\mathrm{I} 5$ of the degraded MEA edge (solid line) than in the central area (segment D5, broken line). On the cathode side, displayed in Fig. 3b, a signal of a defluorinated compound cannot be observed. The decrease of the $\mathrm{C}-\mathrm{F}_{2}$ signal, compared to the dotted peak of the pristine samples, is commonly observed after short operation and is attributed to initial redistribution or washing-out of mobile ionomer particles.

In general, according to XPS characterization, the degradation issues in the ionomer after operation under non-humidified conditions are very small, merely only slightly visible on the anode side in the area of partially lower performance. This degree of degradation is in accordance with the CVs, where a slight reduction of the active area was observed (supplementary data, Fig. S1). The GDL and MPL carbon signals did not show detectable degradation issues. 

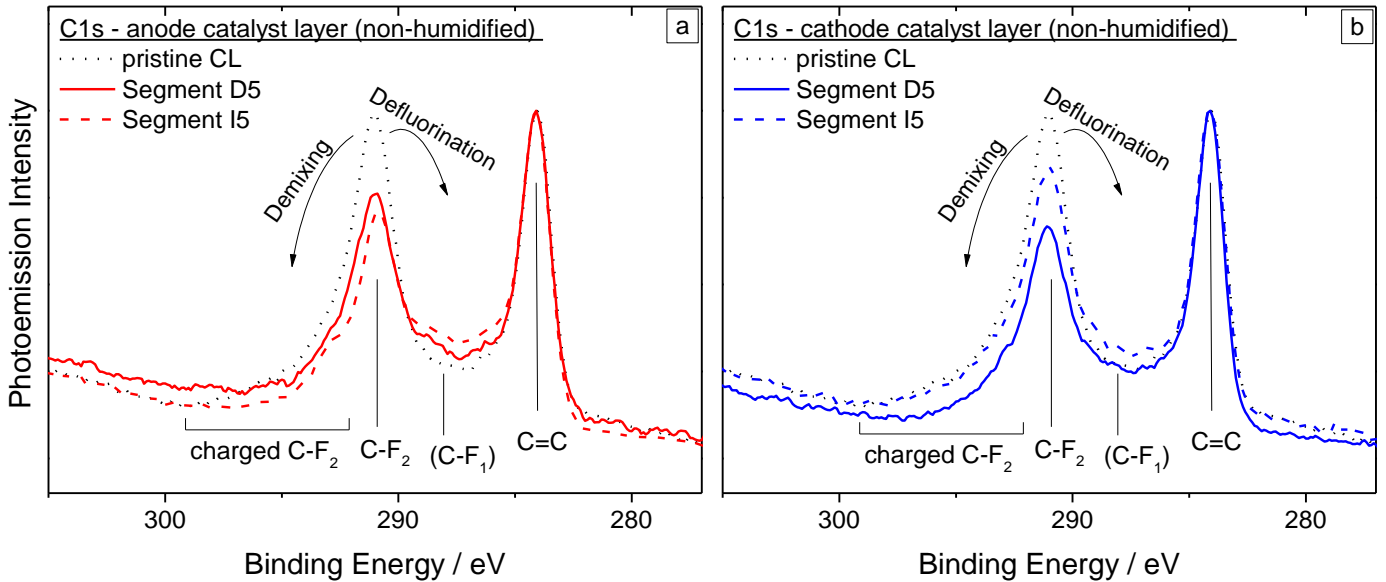

Fig. 3. Carbon photoemission spectra of catalyst layers reveal little degradation of the fluorinated ionomer under non-humidified conditions in central (D5, comp. Fig. 1) and edge areas (I5).

$\mathrm{Ni}$ and $\mathrm{Si}$ were not detected by photoemission (information depth $<10 \mathrm{~nm}$ ), which shows, that these elements (see EDX data in Table 2) are not present at the investigated surfaces, i.e. the interfaces between CL and MPL, while being deposited inside the ionomer containing components.

\subsection{Operation at fully humidified gases}

With the aim of studying in comparison the local degradation processes associated to operation of the cell under fully humidified gas supply, a MEA was operated with watersaturated gases for more than $275 \mathrm{~h}$ under the conditions described in Table 1. The observed evolution of the cell voltage is plotted in Fig. 4a. The voltage is less stable than during operation with dry gases [46]. This fluctuating voltage typically arises when the cell suffers from flooding.

Despite better initial performance and more homogeneous current distribution, the voltage losses rate $\left(164 \mu \mathrm{V} \mathrm{h}^{-1}\right)$ were approx. $12 \%$ higher than for the MEA operated with non-humidified gases (see Fig. 2a).

At BoT, the current density was at its highest in the central area, and did not show the significant drop during the experiment at the right side (segments in columns G, H and I), as was observed at non-humidified conditions (see Fig. 2b). As mentioned above, with non-humidified gases, the current decline is related to water evaporation into the gases, specifically at the cathode inlet, where the gas is far below the saturation point (segments in columns G, H and I, see Fig. 1 and Fig. 2b). In contrast to operation with saturated gases, the current drop is located in the lower part of the cell, corresponding to rows 8,9 and 10 reported in Fig. 1 and Fig. 4b, where the excess of water is expected to accumulate.

A similarity between both experiments is the heterogeneous evolution of voltages leading to higher losses in specific areas. For fully humidified operation, not the upper area (segments $\mathrm{C} 1$ and $\mathrm{C} 2$ ), but the bottom area (segment E10) showed this voltage drop. As 
reported later in the SEM/EDX section (3.2.1), this can also be linked to contamination from other fuel cell components.

a)

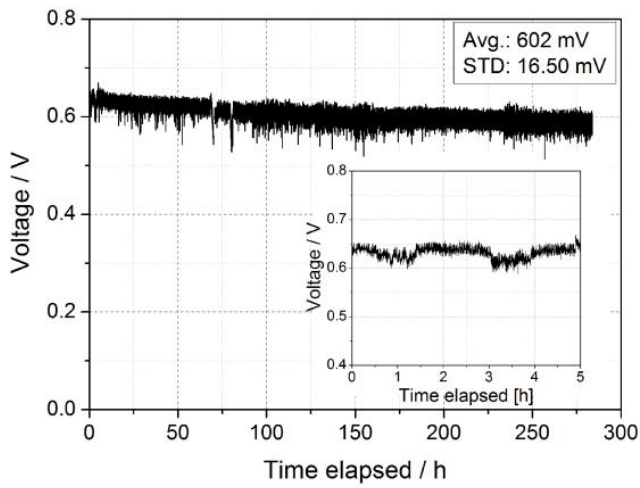

b) BoT

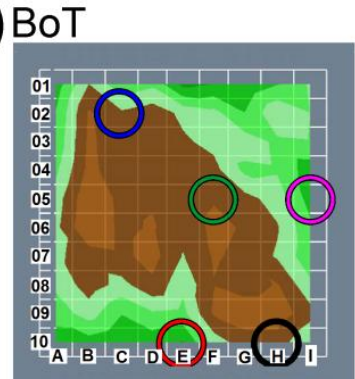

EoT

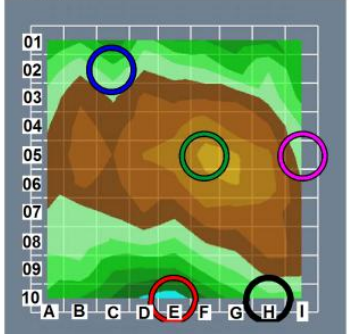

C)

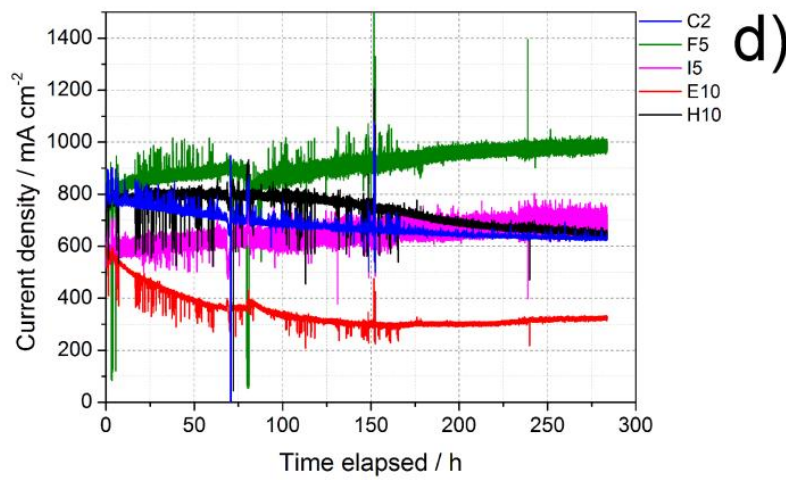

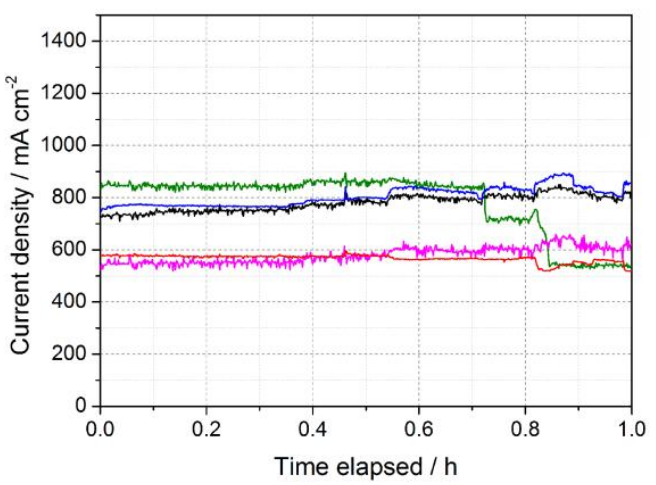

Fig. 4. Cell operation under water-saturated gas supply (approx. $100 \% \quad$ RH). a) Development of cell voltage during the approx. $300 \mathrm{~h}$ long-term experiment at $0.7 \mathrm{~A} \mathrm{~cm}^{-2}$ and $60{ }^{\circ} \mathrm{C}$. The inset plot shows the voltage decay in the first $5 \mathrm{~h}$. b) Current density plots at BoT and EoT. The colored circles indicate the segments that underwent ex-situ analyses (see Section 3.2.1 and 3.2.2). c) Cell current density evolution during the long-term experiment and d) during the first hour for the segments analyzed ex-situ and displayed in b).

The segment-specific current density development of the MEA operated with watersaturated gases (see Fig. 4) shows both similarities and differences compared to nonhumidified operation. A difference is that at fully humidified operation, in contrast to non-humidified operation, the cell did not exhibit an equilibration phase at the beginning of the test (see Fig. 2). During the experiment, the voltage fluctuated with sporadic severe drops because of temporary flooding, as mentioned above. Similarly to the case of dry operation, the current density also changed locally during operation at wet conditions. But this time, the current density decreased more strongly in the segments situated at the beginning of the first serpentine channel after the cathode inlet (F10, G10, and H10). Here, most likely, water accumulated. Besides, punctual pronounced degradation also occurred, however not in C2, but at the opposite border in E10.

In this case, CVs indicated an overall lower ECSA loss on both electrodes, with a reduction between BoT and EoT of $5.2 \%$ and $2.9 \%$ at anode and cathode, respectively. But in this case, contrarily to what we observed for the dry operation, a slightly higher reduction of ECSA was recorded at the anode than at the cathode. (CVs see Fig. S5 in Supplementary Data). 
As can be seen from Table 3, among the analyzed segments, the segments C2, E10, and H10 were contaminated with $\mathrm{Ni}$. The local distribution in this case is similar to the operation at non-humidified conditions (see Table 2) with the difference that at $100 \%$ RH Ni concentrated at E10 and migrated additionally into its neighboring segment H10.

Regarding the Si contamination, the contamination level at the electrodes was lower at fully humidified than at non-humidified conditions. Table 3 shows that at $100 \% \mathrm{RH}$, only the two segments $\mathrm{C} 2$ and I5 exhibited a distinct Si content in the cathode with a maximum of $0.6 \pm 0.9 \mathrm{wt} \% \mathrm{Si}$ at the cathode side of I5. In contrast, at non-humidified conditions, $\mathrm{Si}$ was detected in the electrodes in all the analyzed segments, with up to $2.4 \pm 1.3 \mathrm{wt} \% \mathrm{Si}$ at the cathode side of H10 (see Table 2). From this difference in the Si content in the electrodes, it can be concluded that Si species were flushed out of the cell at high level of humidification, whereas they accumulated in the cell at dry conditions as suggested in [21]. An alternative explanation would be to consider a lower rate of decomposition of the silicone sealing at high humidification.

Pt contamination depended similarly on RH as Si. Pt was also detected in fewer segments at operation under full humidification. Data on membrane thickness did not indicate membrane thinning.

\subsubsection{X-ray photoelectron spectroscopic studies (XPS)}


Similarly to ECSA and SEM/EDX data, the carbon 1s photoemission signals present considerable degradation in the MEA after operation at $100 \%$ RH. Fig. 5 shows the signals of the CLs of anode (c) and cathode (d). Samples from the central area (F5, solid line) and the edge (I5, broken line) of the active area are compared to a pristine CL (dotted line). All of the operated samples show the signal of partially defluorinated ionomer at $\sim 288 \mathrm{eV}$ (labelled $\mathrm{C}-\mathrm{F}_{1}$ ). The degree of degradation in the investigated samples after operation at $100 \% \mathrm{RH}$ is also higher on the anode than on the cathode side. The ionomer signal $\left(\mathrm{C}-\mathrm{F}_{2}\right)$ of the anode $\mathrm{CL}$ is reduced to approximately the height of the arising $\mathrm{C}_{-} \mathrm{F}_{1}$ signal. The same type of degradation is present, but less drastically, at the cathode CL. In both anode and cathode, the degradation is more pronounced in the edge segment I5 than in the inner segment F5.
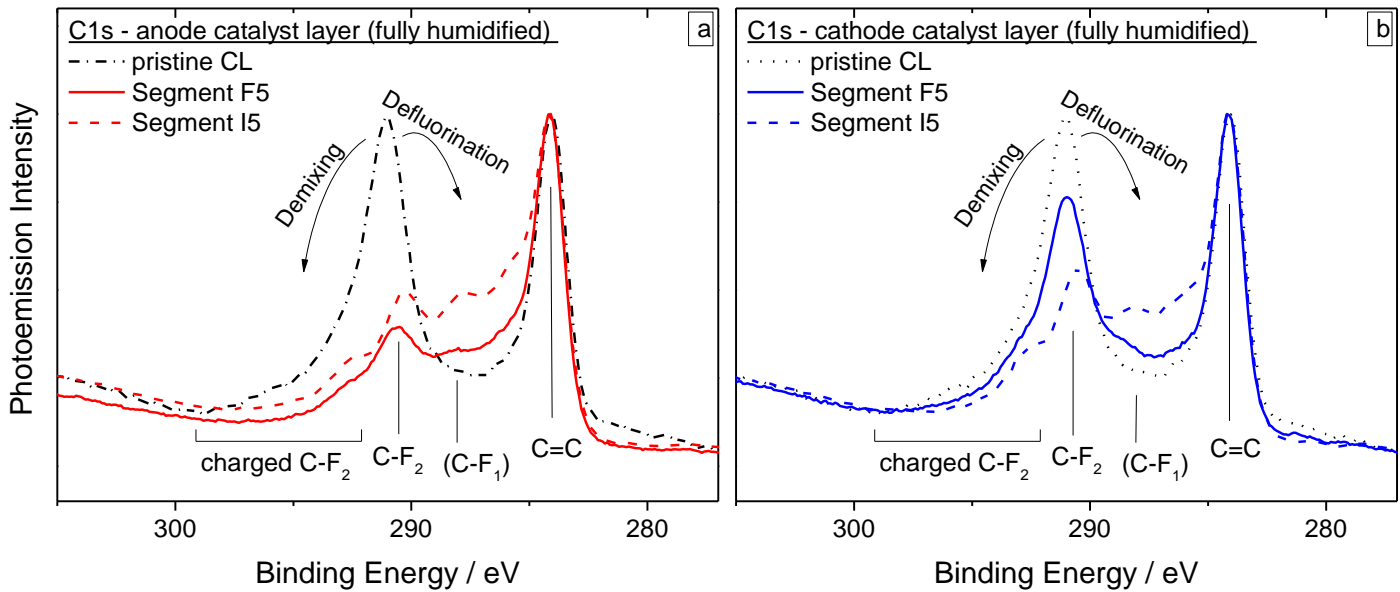

Fig. 5. Carbon photoemission spectra of catalyst layers reveal distinct ionomer defluorination under fully humidified conditions, in particular on the anode (a) and close to the gas inlet (segment I5) of the cathode (b).

Apart from the carbon signals, very small traces of Ni were observed in segment E10 of both CLs. The abundance of $\mathrm{Ni}$ in the membrane, the electrodes and even in the reinforcement layer (see Table 3), detected by SEM/EDX and the overall absence of Ni from photoemission data (information depth $<10 \mathrm{~nm}$ ) shows, that this contamination did not agglomerate at the interface to the MPL but is distributed through the membrane. The Ni trace detected in the interfaces of segment E10 correlates with the increased bulk EDX signal in this edge segment (see supplementary data, Fig. S4).

\section{Discussion}

In the previous section, the impact of non-humidified and fully humidified gases on cell performance loss was evaluated. To sum up, the operation with water-saturated gases caused higher performance losses compared to non-humidified operation on a time scale of $300 \mathrm{~h}$. By post-mortem examination, different degradation processes were identified: defluorination of the GDL, Pt dissolution with subsequent agglomeration and deposition in the membrane, contamination of the electrodes and the membrane by Ni-ions stemming from the coating of the bipolar plate, and contamination of the electrodes by Si-species from the silicon based gasket. In addition, it is expected that operation with non-humidified gases dried the membrane locally resulting in reduced conductivity. 
The simultaneous occurrence of these processes suggests a complex degradation of the operated MEAs. To clarify the significance of each single process and the role of RH, we will analyse and interpret our data.

To begin with, it has to be noted that, surprisingly, operation at non-humidified gases led to lower performance losses. In previous studies with older types of membranes, low RH levels caused a significantly higher degradation [15], [66]. This significant difference between literature and our experiment can obviously be linked to the advanced Nafion ${ }^{\circledR}$ XL membrane used in our experiment. This membrane is specifically optimized for low $\mathrm{RH}$ operation by incorporation of $\mathrm{Si}$-based particles in the membrane. It seems that thereby water can effectively be retained in the ionomer so that it is far less sensitive to drying-out. Due to this improvement and the additional reinforcement layer inside the membrane, the membrane is less prone to structural damage. However, low RH still decreases performance.

\subsection{Evaluation of the reversibility the degradation}

In order to evaluate the impact of the contaminants on the degradation, next, we will distinguish between reversible and irreversible degradation. This is done by comparing the degradation within the $300 \mathrm{~h}$ test with saturated and non-humidified gases, respectively, to the degradation determined from the E-j curves at $50 \% \mathrm{RH}$ (for both MEAs).

The changes in current density distribution during the degradation test (compare the two left plots in Fig. 6) show that the operation with non-humidified gases results in a more inhomogeneous current loss than operation with saturated gases. This can be quantified comparing the segment specific standard deviation of the cell current after $300 \mathrm{~h}$ running test at non-humidified (41.0\%) and saturated (14.6\%) gases.

It is evident that feeding the cell with non-humidified gases produces higher performance losses in the segments under the influence of cathode inlet columns G, H, and I (see Fig. 1). However, by subsequently operating the MEA at $50 \% \mathrm{RH}$, the current distribution became more homogeneous again, resulting in a similar homogeneity for both MEAs. This can be corroborated looking at the segment specific standard deviation of the cell current; these are after recovery of $26.8 \%$ and $20.7 \%$ respectively for non-humidified and saturated gas streams.

This shows that dry gases locally caused reversible degradation at cathode inlet (columns $\mathrm{G}, \mathrm{H}$, and I) which could be partly recovered by humidifying the MEA. The fraction of the reversible losses made up more than half of the losses. For example, in the area bounded by $\mathrm{H} 3$ to $\mathrm{I} 10$ (cathode inlet section without $\mathrm{Ni}$ contaminated area), the average losses were reduced from $60 \%$ to $26 \%$. In fact at $110 \mathrm{~A}$, the losses in this area decreased further to $1 \%$ (see Fig. 7), i.e. they were almost completely recovered. The fact that the total performance loss did not increase when this reversible local degradation occurred indicates that the local performance losses were not limited and could be compensated by a performance increase in other cell regions like the center and anode inlet/cathode outlet (left side in the diagram). 


\section{in E-j curves @ $\mathbf{5 0}$ \% RH}

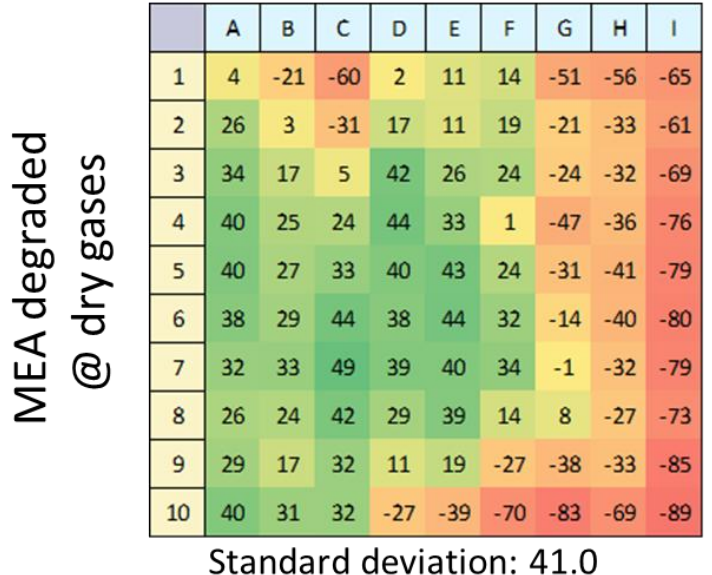

\begin{tabular}{|c|c|c|c|c|c|c|c|c|c|}
\hline & $\mathrm{A}$ & B & c & D & $\mathrm{E}$ & $F$ & $\mathrm{G}$ & $\mathrm{H}$ & 1 \\
\hline 1 & 7 & -26 & -66 & -20 & -16 & -18 & -67 & -49 & -40 \\
\hline 2 & 16 & -4 & -43 & 3 & 0 & 3 & -40 & -31 & -39 \\
\hline 3 & 24 & 10 & -3 & 25 & 16 & 21 & -20 & -16 & -32 \\
\hline 4 & 31 & 15 & 18 & 27 & 24 & 6 & -22 & -21 & -30 \\
\hline 5 & 30 & 16 & 23 & 25 & 33 & 19 & -17 & -25 & -32 \\
\hline 6 & 31 & 17 & 26 & 25 & 38 & 18 & -14 & -24 & -34 \\
\hline 7 & 27 & 16 & 27 & 24 & 32 & 21 & -12 & -23 & -34 \\
\hline 8 & 21 & 15 & 25 & 19 & 40 & 9 & -11 & -24 & 14 \\
\hline 9 & 20 & 10 & 18 & 5 & 19 & -14 & -26 & -24 & -38 \\
\hline 10 & 37 & 29 & 23 & -22 & -23 & -37 & -42 & -33 & -40 \\
\hline
\end{tabular}

during durability test @ 100 \% RH

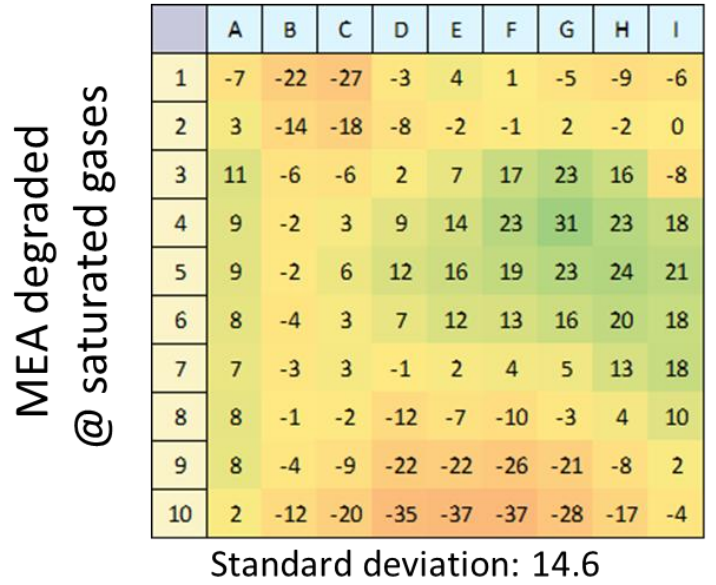

in E-j curves @ 50 \% RH

Fig. 6. Change in current distribution at $700 \mathrm{~mA} \mathrm{~cm}^{-2}$ (=EOT-BOT/BOT $* 100$ in \%) due to the degradation test. Comparison between data recorded during long term test (non-humidified or fully humidified gases) and E-j curves (50\% RH) before and after test operation.

Based on our post-mortem data, the reversible losses can be attributed to the ionomer drying and/or the $\mathrm{Si}$ contamination. This becomes obvious in segments where $\mathrm{Si}$ contamination dominated, e.g. H10 and I5. Here, the voltage losses could be almost completely recovered whereas the losses remain significant in the segments with $\mathrm{Ni}$ contamination (C2 and E10).

As was already mentioned, silicone is assumed to degrade by de-crosslinking and chain scissoring. [61]-[63]. According to this and the fact that $\mathrm{Si}$ is not bonded ionically in silicone, Si should remain in its non-ionic state when being present in silicone fragments. Thus, it is unlikely that Si penetrates into the membrane via the ionic pathway or by permeation. Furthermore, it was reported that silicone species do not adsorb on Pt [76]. Therefore, we conclude that $\mathrm{Si}$ species had deposited at dry conditions in the pores of the electrodes and GDL, mainly in the cathode inlet section which is most affected by drying [6], [46]. The fact that $\mathrm{Si}$ was present after the subsequent increase in RH (50\% RH 
during E-j curve measurement) shows that, once deposited, it remains in the MEA and cannot be removed easily by the humidified gas stream, probably due to agglomeration. However, operation with saturated gases reduced this initial deposition. This means that in this case, $\mathrm{Si}$ species were dragged out of the cell by water or the silicone decomposition was mitigated by high humidification.

As our results show, $\mathrm{Si}$ contamination causes reversible degradation mainly in dry conditions. Si traces are assumed to reduce catalytic activity via blocking of oxygen transport. Sethuraman et al. observed a reduction in ORR current in ring disc studies when siloxane was present in the electrode[67]. They suspect that Si induces local hydrophobicity, with the result of local water starvation. Since gas transport occurs in aqueous media, as a consequence, gas transport is blocked. This assumption is backed by our experiment results as this effect occurred only in dry conditions and in the region which is most sensitive to drying-out. Apparently, the Si contamination amplifies the sensitivity to water.

\subsection{Current specific performance losses in the E-j curve}

In order to to account for the complexity of PEMFC degradation losses are examined based on the different sections in the E-j curve.As shown in Fig. 7a, RH has a significant influence on the specific losses. The reason for the higher performance losses due to the operation at $100 \% \mathrm{RH}$ can be found in the activation region $\left(<200 \mathrm{~mA} \mathrm{~cm}^{-2}\right)$. Obviously, the activation over potential became considerably higher for $100 \% \mathrm{RH}$ than for nonhumidified operation. In contrast, ohmic losses were similar at both conditions, as is indicated by the slope of the curve between 200 and $700 \mathrm{~mA} \mathrm{~cm}{ }^{-2}$. But a further difference can be observed at higher currents $\left(>700 \mathrm{~mA} \mathrm{~cm}^{-2}\right)$. Here, the restricted reactant flow limited the current and therefore caused additional mass transport losses for both MEAs. However, these losses emerge at lower current densities for the MEA operated at non-humidified gases.

\subsubsection{Activation losses}

Fig. $7 \mathrm{~b}$ demonstrates that for both experiments, the highest performance losses occurred mainly in three specific areas (C1/D1, G1/H1, and D10/E10/F10) of which two verifiably contained $\mathrm{Ni}$ (C2 and E10). Thus, the activation losses can be attributed to $\mathrm{Ni}$ contamination. The strong degradation can be explained by the negative effect of metal cations on reaction kinetics. Studies by Okada et al. [68], [69] and Durst et al. [70] showed that ORR kinetics are reduced at the Pt/ionomer interface by the presence of metal cations; however, without adsorbing into the Pt surface as their CV results show. The authors concluded that the foreign cations cause a structural change of the electric double layer and/or increase the formation of the Pt oxide layer. A further explanation for activation losses was given by Kienitz et al. [71]. They found that metal cations concentrate in the membrane close to the cathode. This results in locally reduced proton concentration which leads to kinetic losses and a reduced electrochemical potential. It can be noticed that the MEA degraded at $100 \% \mathrm{RH}$ was affected more strongly by the contamination. The higher number of segments with losses (43 vs. 36) point out that $\mathrm{Ni}$ distributed wider within the active area. This can be attributed to the higher water level resulting in an enhanced transport of $\mathrm{Ni}$ ions. 
a)

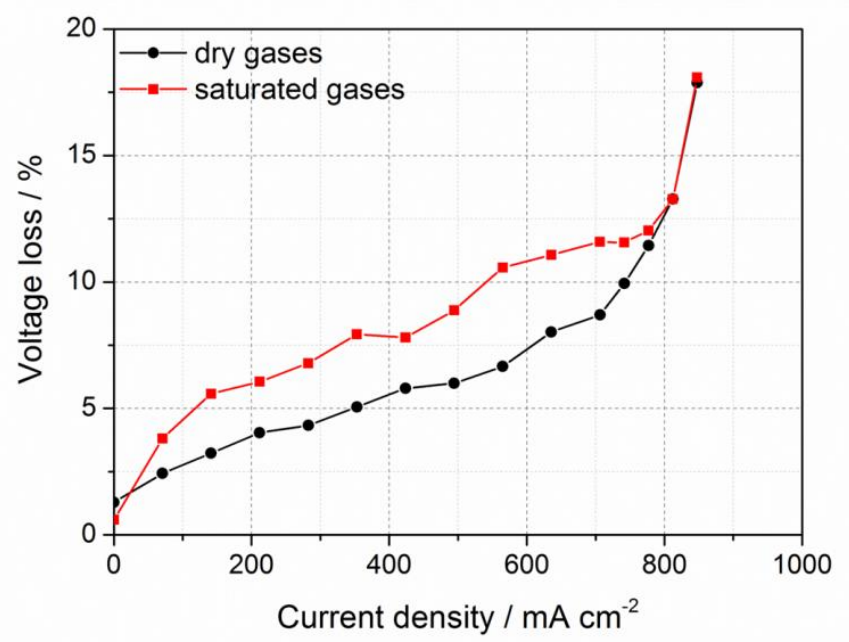

b)

@ $70 \mathrm{~mA} \mathrm{~cm}{ }^{-2}$

@ $495 \mathrm{~mA} \mathrm{~cm} \mathrm{~cm}^{-2}$

@ $775 \mathrm{~mA} \mathrm{~cm}{ }^{-2}$

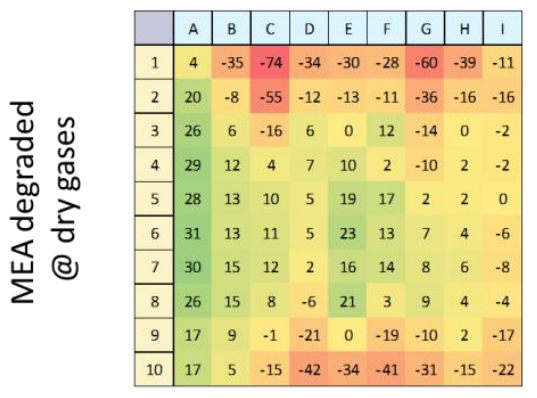

\begin{tabular}{|c|c|c|c|c|c|c|c|c|c|}
\hline & A & B & C & D & $\mathrm{E}$ & $\mathrm{F}$ & G & $\mathrm{H}$ & 1 \\
\hline 1 & 0 & -36 & -69 & -25 & .23 & -24 & .7 & -5 & $5-4$ \\
\hline 2 & 13 & -10 & -48 & 6 & 1 & 1 & -4 & $7-3$ & -4 \\
\hline 3 & 24 & 6 & -8 & 26 & 17 & 21 & -2 & $6-1$ & $3-3$ \\
\hline 4 & 30 & 13 & 13 & 25 & 25 & 4 & -2 & $5-2$ & -3 \\
\hline 5 & 31 & 16 & 20 & 21 & 33 & 18 & -1 & $7-2$ & -3 \\
\hline 6 & 34 & 19 & 25 & 22 & 37 & 16 & -1 & $2-2$ & -3 \\
\hline 7 & 34 & 22 & 29 & 22 & 30 & 20 & -1 & $0-2$ & -3 \\
\hline 8 & 30 & 22 & 28 & 13 & 38 & 8 & 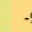 & -2 & 14 \\
\hline 9 & 28 & 19 & 19 & -4 & 15 & -18 & & $3-2$ & -4 \\
\hline 10 & 44 & 38 & 23 & -29 & -25 & & & -3 & -4 \\
\hline
\end{tabular}
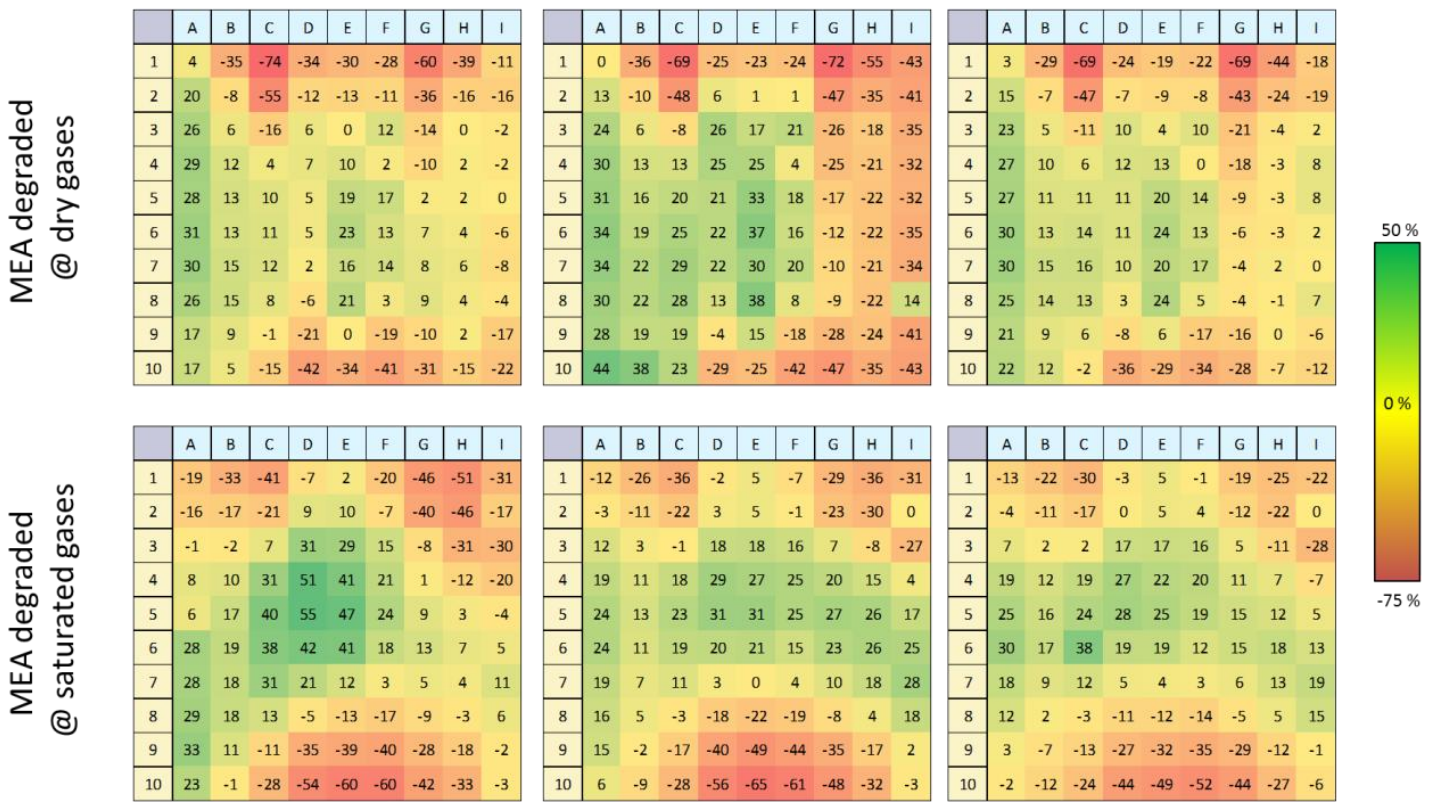

Fig. 7. a) Percentage voltage loss based on E-j curves measured at BoT and EoT for the non-humidified (black) and fully humidified (red) operated MEA. E-j curves were measured in galvanostatic mode at a cell temperature of $80{ }^{\circ} \mathrm{C}$, and under reactants humidification of $50 \% \mathrm{RH}$ (experimental details are reported in section 2.1). b) Distribution of the relative voltage losses. For each MEA, voltage losses are shown from the three different sections of the curve in a) which correspond to activation, ohmic, and mass trasport losses.

\subsubsection{Ohmic losses}

The additional ohmic losses which can be seen from the linear increase of the voltage loss curve in Fig. 7a can also be explained by the Ni contamination. Generally, metal cations in the ionomer were reported to block the sulfonic sites because they have a higher affinity for it than protons [72]-[74]. Since the metal cations are less mobile and allow less water uptake in the membrane than protons (except $\mathrm{Li}^{+}$), contamination by metal cations leads to a loss in conductivity [72], [73], [75], [76]. Furthermore, it has to 

(columns G, H and I) of the MEA operated at non-humidified conditions appear. As already explained, these losses can be related with ionomer drying due to evaporation and/or Si contamination.

\subsubsection{Mass transport losses}

At high currents $\left(>0.7 \mathrm{~mA} \mathrm{~cm}^{-2}\right)$, these local losses are less pronounced. This means the inlet region is reactivated. Probably due to re-hydration of the ionomer caused by the increased electro-osmotic drag and/or due to washing out of the $\mathrm{Si}$ deposits by the increased water transport. However, in contrast to the MEA operated in saturated conditions, the current in this area did not increase. Therefore, this area did not contribute to the compensation of the losses from the $\mathrm{Ni}$ contaminated areas. Thus, we conclude that the compensation capability of the MEA operated at non-humidified conditions was limited due to the additional degradation by $\mathrm{Si}$ contamination and ionomer degradation with the consequence of a steep increase in voltage losses at higher currents (see Fig. 7a). The reasons for this are again local Si contamination and ionomer drying. But besides, this performance loss might have also been the result of a limiting active area since the MEA operated in dry conditions suffered from higher ECSA losses at the cathode. The remaining cathode ECSA was $47 \mathrm{~m}_{\mathrm{Pt}}{ }^{2} \mathrm{~g}_{\mathrm{Pt}}{ }^{-1}$ whereas the MEA operated in saturated conditions had $71 \mathrm{~m}_{\mathrm{Pt}}{ }^{2} \mathrm{~g}_{\mathrm{Pt}}{ }^{-1}$. This observation is in accordance with the reported results that Pt dissolution and ECSA loss is favored under low humidity conditions [44]. Therefore, locally pronounced Pt dissolution in the non-humidified cathode inlet area must be considered as another possible degradation process for the MEA operated with non-saturated gases.

\subsection{Impact of $\mathrm{Ni}$ and $\mathrm{Si}$ contaminants}

In the discussion of the voltage losses, it also becomes obvious that the dependence of $\mathrm{RH}$ in contamination is opposite for $\mathrm{Ni}$ in comparison with $\mathrm{Si}$. High $\mathrm{RH}$ facilitates $\mathrm{Ni}$ contamination but impedes Si contamination. This can be explained by the difference in the chemical state of the contaminants. In contrast to $\mathrm{Si}, \mathrm{Ni}$ is changing its state to ionic $\mathrm{Ni}$ when the metal corrodes and therefore can enter into the ionomer of the electrode and membrane. The incorporation of $\mathrm{Ni}$-ions into the ionomer and their strong ionic bonding to it seems to protect them from being washed out again.

The two contaminants $\mathrm{Ni}$ and Si not only differ in their dependence on RH but also in their impact on degradation. The degradation caused by Ni occurred more slowly than the degradation caused by $\mathrm{Si}$. This becomes obvious from the chronological voltage development in Fig. 2 and Fig. 4. In all the segments which were contaminated with Ni (fully humidified gases: C2, E10 and H10; non-humidified gases: C2 and E10), the voltage declined steadily during a duration of at least ca. 100h. In contrast, Si contamination caused a drop occurring within the first hour. Since Si was only present in the MEA operated with non-humidified gases, this initial period reflects the phase in which this MEA became balanced after the RH change from $100 \%$ (characterization measurement) to $0 \%$ (degradation test). From this we can conclude that Si deposited in the electrodes instantly during this transition phase. This deposition was at least partly irreversible since Si remained there even after another period of operation at $100 \% \mathrm{RH}$ during the EOT characterization. In contrast, $\mathrm{Ni}$ began penetrating slowly and continuously into the ionomer at one point during the test (see in Fig. 2c) blue line). 


\subsection{Ionomer and PTFE defluorination}

Within this study the degradation of advanced membranes was observed most pronounced under fully humidified operation. The important local factor are contaminations from external sources which can be mitigated by careful material selection in the system. However, a difference is observed in the strong defluorination of ionomer in the CL under full humidifcation in Fig. 5. The loss of fluorination should affect the activation losses in particular under full humidication, nevertheless in our case the Ni contamination outweighs the losses

The elimination of fluorine and fluorine containing compounds in PEMFC has been observed in the in form of fluoride in the product water [77] and also by means of membrane thinning [78] in early lifetime investigations. A major focus is on ionomer materials, on membranes [78], and on catalyst layer ionomer [78]-[80], which are prone to radical attack by reaction intermediates [32]. However, the hydrophobic agents in the MPL and the GDL backing are also degraded; a defluorination similar to that of ionomers can be observed. [64] In contrast to ionomers, typically perfluorosulfonic acids with unstable side groups, the hydrophobic PTFE agent of GDLsis much more stable against chemical attacks. However, also this component shows degradation which appears to be mechanistically similar to that of the radical attacks an ionomers.[22] Fig. 8 shows the corresponding XPS spectra of the carbon containing compounds of the GDL components operated without and under full humidification, with the dominant graphite/carbon fibre signal $(284-285 \mathrm{eV})$ and the fluorine containing compounds with binding energies $>286$ eV.[64], [81] Similar to the spectra of the CLs discussed in chapter 3.1.2 and 3.2.2, the signal at $\sim 292$ represents the perfluorinated carbon species " $\mathrm{C}-\mathrm{F}_{2}$ ", present in PTFE. Both the pristine MPL and the GDL backing lose a considerable amount of this compound (within the detection range of $\sim 10 \mathrm{~nm}$ ), which is attributed to a wash-out of weakly fixed material during the first break-in phase before operation of the fuel cell. In particular, in Fig $8 \mathrm{~b}$ the signal of the pristine material shows a peak at $\sim 300 \mathrm{eV}$, due to the local charging of the weakly bound material, and which is not present in all the other spectra recorded after break-in procedure and operation. The MPL (Fig. 8a) shows relatively little defluorination, visible as small signals at $288 \mathrm{eV}$, yet more pronounced after fully humidified operation (solid lines). The same degradation processes are much more distinct in the GDL backing, and, similarly, most pronounced after fully humidified operation: The " $\mathrm{C}-\mathrm{F}_{1}$ " signal is filling up the valley between the main signals, and the broadness hints to a variety of partially defluorinated compounds (Fig. 8b, solid lines). The correlation with humidity suggests, that intermediately generated radical peroxide ions are able to travel from CL even to the outer endge of the GDL, aided by a high humidification level. 

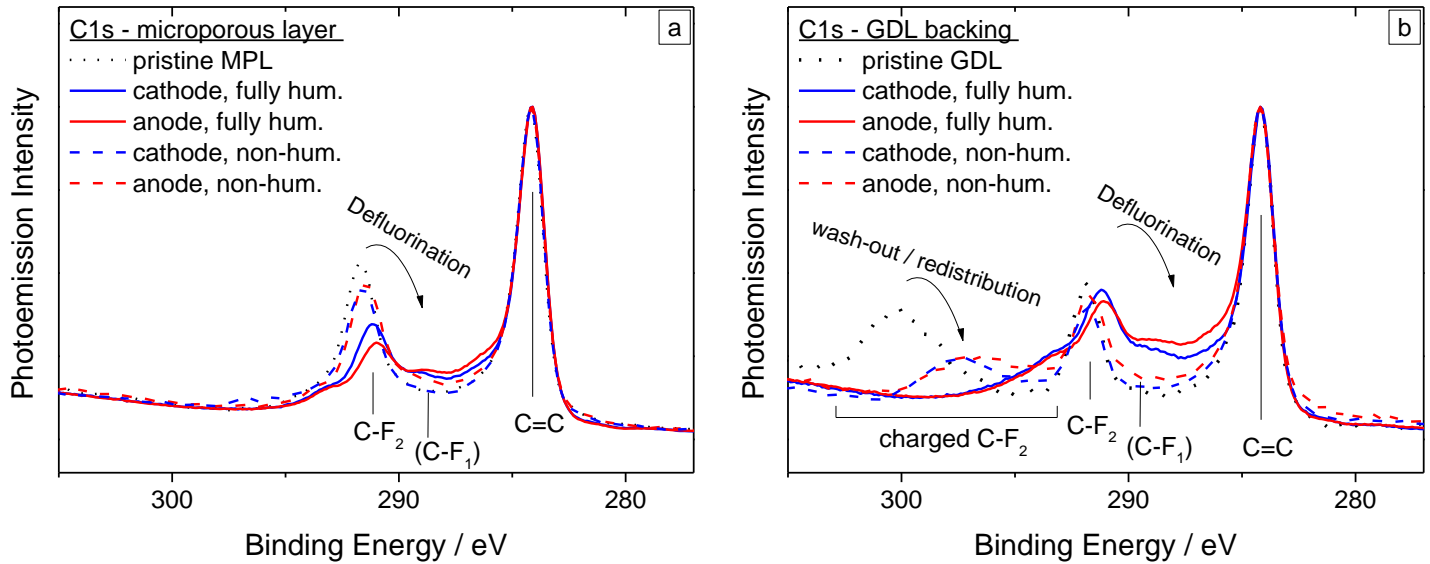

Fig. 8. Carbon photoemission spectra of microporous layer and GDL backing b) in segment I5 - partial defluorination of PTFE $(292 \mathrm{eV})$ to a lower oxidation state $(<290 \mathrm{eV})$, in particular unter fully humidified conditions

However, the degradation of the hydrophobic agent, which reduces the liquid water repellant properties [64] does not result in a more pronounced heterogeneity of performance losses, as displayed in Fig. 7b. The degree of degradation is coarsely linked to areas of higher catalytic activity, and is less striking in the investigated edge areas of the cell (not displayed).

\section{Conclusions}

The present study investigates and compares degradation processes in PEMFC associated to operation under fully and non-humidified gases. By evaluating local performance losses (irreversible as well as reversible losses), degradation was linked to the influence of RH as well as to different mechanisms such as contamination of the electrodes and the membrane by Ni-ions stemming from the coating of the bipolar plate, contamination of the electrodes by $\mathrm{Si}$-species from the silicon based gasket, ionomer dehydration, and $\mathrm{Pt}$ dissolution. Additionally pronounced defluorination of ionomer in the electrodes and GDL components were observed.

It was seen that degradation was lower with non-humidified gases than with fully humidified gases. This can be linked to the latest improvement of Nafion ${ }^{\circledR}$ membranes by the manufacturer. Obviously, water can be successfully retained inside the ionomer by the incorporation of Si-based particles. Although performance is still lower at low RH, this development facilitates water management and reduces, in combination with the reinforcement layer, the danger of membrane damage due to dehydration.

Our local degradation investigations show the pronounced impact of $\mathrm{RH}$ on the heterogeneity during the degradation process:

- Under non-humidified gases, the cathode inlet region was highly affected by mainly two different degradation processes. Firstly, the evaporation in the air inlet region led to membrane dehydration, decreasing membrane conductivity. Secondly, the deposition of $\mathrm{Si}$ species in the pores of the electrodes and GDL diminish the cell activity due to increased gas transport resistances. 
Furthermore, Pt dissolution contributed partially to the degradation at this area, due to the fact that at high currents the available Pt surface area is crucial to current limitation. Moreover, Ni contamination was also detected; primarily in the edges of the cell, generating a strong irreversible degradation in these areas. Degradation by Si contamination and membrane dehydration was found to be partially reversible.

- With fully humidified gases the liquid water tends to accumulate at the bottom of the cell, where it causes higher level of degradation. Since liquid water prevents the Si deposition, the observed degradation can be linked to Ni contamination as confirmed by the post mortem analysis. With a high level of humidification, the defluorination of ionomer in the catalyst layer and of hydrophobicity agent in the GDL is considerably intensified. For the latter, there is no direct impact, and specially no local impact on performance.

Compared with Si contamination or membrane dehydration, performance losses due to $\mathrm{Ni}$ contamination occur more slowly. Nevertheless, the $\mathrm{Ni}$ contamination generates irreversible degradation.

Although differences in the PTFE defluorination were found in the CL, MPL, and GDL between fully and non-humidified gases, local degradation is dominated by contaminants in particular Ni in our case.

In general, our work proves the importance of the spatially resolved diagnosis of fuel cells. Only this allows the identification and separation of the degradation processes in a complex performance loss evolution .

\section{Acknowledgments}

This work was supported by the European Union's Seventh Framework Programme (FP7/2007-2013) for the Fuel Cells and Hydrogen Joint Technology Initiative under grant agreement $\mathrm{n}^{\circ} 325239$ (Nano-CAT). The authors would also like to thank H. Sander at DLR for helpful suggestions and discussions as well as A. Lützner for performing XPS measurements.

\section{References}

[1] J. Kurtz, S. Sprik, C. Ainscough, and G. Saur, "Fuel Cell Electric Vehicle Evaluation," DOE 2015 Annual Merit Review. 2015.

[2] U.S. Department of Energy (DOE), "Fuel Cell Technical Team Roadmap." 2013.

[3] K. C. Neyerlin, H. a. Gasteiger, C. K. Mittelsteadt, J. Jorne, and W. Gu, "Effect of Relative Humidity on Oxygen Reduction Kinetics in a PEMFC," J. Electrochem. Soc., vol. 152, p. A1073, 2005.

[4] F. N. Büchi, “Operating Proton Exchange Membrane Fuel Cells Without External Humidification of the Reactant Gases," J. Electrochem. Soc., vol. 144, no. 8, p. 2767, 1997. 
[5] J. R. Atkins, S. C. Savett, and S. E. Creager, "Large-scale current fluctuations in PEM fuel cells operating with reduced feed stream humidification," J. Power Sources, vol. 128, no. 2, pp. 201-207, 2004.

[6] D. G. Sanchez and P. L. Garcia-Ybarra, "PEMFC operation failure under severe dehydration," Int. J. Hydrogen Energy, vol. 37, no. 8, pp. 7279-7288, 2012.

[7] H. K. Hsuen and K. M. Yin, "Performance equations of proton exchange membrane fuel cells with feeds of varying degrees of humidification," Electrochim. Acta, vol. 62, pp. 447-460, 2012.

[8] S. Vengatesan, H. J. Kim, E. A. Cho, S. U. Jeong, H. Y. Ha, I. H. Oh, S. A. Hong, and T. H. Lim, "Operation of a proton-exchange membrane fuel cell under nonhumidified conditions using thin cast Nafion membranes with different gasdiffusion media," J. Power Sources, vol. 156, no. 2, pp. 294-299, 2006.

[9] H.-T. Kim, K.-Y. Song, T. V. Reshetenko, S.-I. Han, T.-Y. Kim, S.-Y. Cho, M.-K. Min, G.-S. Chai, and S.-C. Shin, "Electrochemical analysis of polymer electrolyte membrane fuel cell operated with dry-air feed," J. Power Sources, vol. 193, no. 2, pp. 515-522, 2009.

[10] Y. Lee, B. Kim, and Y. Kim, “An experimental study on water transport through the membrane of a PEFC operating in the dead-end mode," Int. J. Hydrogen Energy, vol. 34, no. 18, pp. 7768-7779, 2009.

[11] J. Benziger, E. Chia, J. F. Moxley, and I. G. Kevrekidis, "The dynamic response of PEM fuel cells to changes in load," Chem. Eng. Sci., vol. 60, no. 6, pp. 1743-1759, 2005 .

[12] D. G. Sanchez, D. G. Diaz, R. Hiesgen, I. Wehl, and K. A. Friedrich, “Oscillations of PEM fuel cells at low cathode humidification," J. Electroanal. Chem., vol. 649, no. 1-2, pp. 219-231, 2010 .

[13] D. Garcia Sanchez, A. Ortiz, and K. A. Friedrich, "Oscillation of PEFC under Low Cathode Humidification: Effect of Gravitation and Bipolar Plate Design," ECS Trans., vol. 58, no. 1, pp. 209-221, 2013.

[14] T. Colinart, A. Chenu, S. Didierjean, O. Lottin, and S. Besse, "Experimental study on water transport coefficient in Proton Exchange Membrane Fuel Cell," J. Power Sources, vol. 190, no. 2, pp. 230-240, 2009.

[15] S. D. Knights, K. M. Colbow, J. St-Pierre, and D. P. Wilkinson, “Aging mechanisms and lifetime of PEFC and DMFC," J. Power Sources, vol. 127, no. 12, pp. 127-134, Mar. 2004. 
[16] E. Endoh, S. Terazono, H. Widjaja, and Y. Takimoto, "Degradation Study of MEA for PEMFCs under Low Humidity Conditions," Electrochem. Solid-State Lett., vol. 7, no. 7, p. A209, 2004.

[17] J. Yu, T. Matsuura, Y. Yoshikawa, M. Nazrul Islam, and M. Hori, "Lifetime behavior of a PEM fuel cell with low humidification of feed stream," Phys. Chem. Chem. Phys., vol. 7, no. 2, p. 373, 2005.

[18] J. Yu, T. Matsuura, Y. Yoshikawa, M. N. Islam, and M. Hori, "In Situ Analysis of Performance Degradation of a PEMFC under Nonsaturated Humidification," Electrochem. Solid-State Lett., vol. 8, no. 3, p. A156, 2005.

[19] X. Huang, R. Solasi, Y. U. E. Zou, M. Feshler, K. Reifsnider, D. Condit, S. Burlatsky, and T. Madden, "Mechanical Endurance of Polymer Electrolyte Membrane and PEM Fuel Cell Durability," J. Polym. Sci. Part B Polym. Phys., vol. 44, no. 16, pp. 2346-2357, 2006.

[20] B. Sompalli, B. A. Litteer, W. Gu, and H. A. Gasteiger, "Membrane Degradation at Catalyst Layer Edges in PEMFC MEAs," J. Electrochem. Soc., vol. 154, no. 12, p. B1349, 2007.

[21] M. Inaba, H. Yamada, R. Umebayashi, M. Sugishita, and A. Tasaka, "Membrane Degradation in Polymer Electrolyte Fuel Cells under Low Humidification Conditions," Electrochemistry, vol. 75, no. 207, 2007.

[22] V. Sethuraman, J. W. Weidner, A. T. Haug, and L. V. Protsailo, "Durability of Perfluorosulfonic Acid and Hydrocarbon Membranes: Effect of Humidity and Temperature," J. Electrochem. Soc., vol. 155, no. 2, p. B119, 2008.

[23] H. Xu, R. Borup, E. Brosha, F. Garzon, and B. Pivovar, "The Effect of Relative Humidity on Membrane Degradation Rates and Mechanisms in Proton Exchange Membrane Fuel Cells," ECS Trans., vol. 6, no. 13, pp. 51-62, 2007.

[24] A. B. LaConti, M. Hamdan, and R. C. McDonald, "Mechanisms of Membrane Degradation," in Handbook of Fuel Cells: Fundamentals, Technology and Applications, Vol. 3., John Wiley., vol. 3, W. Vielstich, A. Lamm, and H. Gasteiger, Eds. Chicester, England, 2003, pp. 647-663.

[25] L. Kim, C. G. Chung, Y. W. Sung, and J. S. Chung, "Dissolution and migration of platinum after long-term operation of a polymer electrolyte fuel cell under various conditions," J. Power Sources, vol. 183, no. 2, pp. 524-532, Sep. 2008.

[26] T. Madden, D. Weiss, N. Cipollini, D. Condit, M. Gummalla, S. Burlatsky, and V. Atrazhev, "Degradation of Polymer-Electrolyte Membranes in Fuel Cells," J. Electrochem. Soc., vol. 156, no. 5, pp. B657-662, 2009. 
[27] A. Ohma, S. Suga, S. Yamamoto, and K. Shinohara, "Membrane Degradation Behavior during Open-Circuit Voltage Hold Test," J. Electrochem. Soc., vol. 154, no. 8, pp. B757-760, 2007.

[28] N. Hasegawa, T. Asano, T. Hatanaka, M. Kawasumi, and Y. Morimoto, "Degradation of Perfluorinated Membranes Having Intentionally Formed Pt-Band," ECS Trans., vol. 16, no. 2, pp. 1713-1716, 2008.

[29] A. Ohma, S. Yamamoto, and K. Shinohara, "Membrane degradation mechanism during open-circuit voltage hold test," J. Power Sources, vol. 182, no. 1, pp. 39-47, Jul. 2008.

[30] D. Zhao, B. L. Yi, H. M. Zhang, and M. Liu, "The effect of platinum in a Nafion membrane on the durability of the membrane under fuel cell conditions," J. Power Sources, vol. 195, no. 15, pp. 4606-4612, Aug. 2010.

[31] A. Pozio, R. F. Silva, M. De Francesco, and L. Giorgi, "Nafion degradation in PEFCs from end plate iron contamination," Electrochim. Acta, vol. 48, no. 11, pp. 1543-1549, May 2003.

[32] T. Kinumoto, M. Inaba, Y. Nakayama, K. Ogata, R. Umebayashi, A. Tasaka, Y. Iriyama, T. Abe, and Z. Ogumi, "Durability of perfluorinated ionomer membrane against hydrogen peroxide," J. Power Sources, vol. 158, no. 2, pp. 1222-1228, Aug. 2006.

[33] M. Inaba, T. Kinumoto, M. Kiriake, R. Umebayashi, A. Tasaka, and Z. Ogumi, "Gas crossover and membrane degradation in polymer electrolyte fuel cells," Electrochim. Acta, vol. 51, no. 26, pp. 5746-5753, Aug. 2006.

[34] K. D. Baik, B. K. Hong, and M. S. Kim, "Effects of operating parameters on hydrogen crossover rate through Nafion ${ }^{\circledR}$ membranes in polymer electrolyte membrane fuel cells," Renew. Energy, vol. 57, pp. 234-239, Sep. 2013.

[35] L. Liu, A. Chakma, and X. Feng, "Gas permeation through water-swollen hydrogel membranes," J. Memb. Sci., vol. 310, no. 1-2, pp. 66-75, Mar. 2008.

[36] G. Jerkiewicz, G. Vatankhah, J. Lessard, M. P. Soriaga, and Y.-S. Park, "Surfaceoxide growth at platinum electrodes in aqueous H2SO4," Electrochim. Acta, vol. 49, no. 9-10, pp. 1451-1459, Apr. 2004.

[37] D. A. Harrington, "Simulation of anodic Pt oxide growth," J. Electroanal. Chem., vol. 420, no. i, pp. 101-109, 1997.

[38] B. E. Conway, B. Barnett, H. Angerstein-Kozlowska, and B. V. Tilak, “A surfaceelectrochemical basis for the direct logarithmic growth law for initial stages of extension of anodic oxide films formed at noble metals," J. Chem. Phys., vol. 93, no. 1990, p. $8361,1990$. 
[39] X. Wang, R. Kumar, and D. J. Myers, "Effect of Voltage on Platinum Dissolution," Electrochem. Solid-State Lett., vol. 9, no. 5, pp. 225-227, 2006.

[40] Y. Sugawara, T. Okayasu, A. P. Yadav, A. Nishikata, and T. Tsuru, "Dissolution Mechanism of Platinum in Sulfuric Acid Solution,” J. Electrochem. Soc., vol. 159, no. 11, pp. F779-F786, Sep. 2012.

[41] R. M. Darling and J. P. Meyers, "Kinetic Model of Platinum Dissolution in PEMFCs,” J. Electrochem. Soc., vol. 150, no. 11, pp. A1523-1527, 2003.

[42] H. Xu, R. Kunz, and J. M. Fenton, "Investigation of Platinum Oxidation in PEM Fuel Cells at Various Relative Humidities," Electrochem. Solid-State Lett., vol. 10, no. 1, p. B1, 2007.

[43] W. Bi, Q. Sun, Y. Deng, and T. F. Fuller, "The effect of humidity and oxygen partial pressure on degradation of $\mathrm{Pt} / \mathrm{C}$ catalyst in PEM fuel cell," Electrochim. Acta, vol. 54, no. 6, pp. 1826-1833, Feb. 2009.

[44] V. Sethuraman, J. W. Weidner, A. T. Haug, S. Motupally, and L. V. Protsailo, "Hydrogen Peroxide Formation Rates in a PEMFC Anode and Cathode," J. Electrochem. Soc., vol. 155, no. 1, p. B50, 2008.

[45] H. Xu, Y. Song, H. R. Kunz, and J. M. Fenton, "Effect of Elevated Temperature and Reduced Relative Humidity on ORR Kinetics for PEM Fuel Cells," J. Electrochem. Soc., vol. 152, p. A1828, 2005.

[46] D. G. Sanchez, T. Ruiu, K. A. Friedrich, J. Sanchez-Monreal, and M. Vera, "Analysis of the Influence of Temperature and Gas Humidity on the Performance Stability of Polymer Electrolyte Membrane Fuel Cells," J. Electrochem. Soc., vol. 163, no. 3, pp. F150-F159, 2015.

[47] T. Ruiu, A. M. Dreizler, J. Mitzel, and E. Gülzow, "Evaluation of a $2.5 \mathrm{kWel}$ automotive low temperature PEM fuel cell stack with extended operating temperature range up to $120^{\circ}$ C," J. Power Sources, vol. 303, pp. 257-266, 2016.

[48] M. Schulze, E. Gülzow, S. Schönbauer, T. Knöri, and R. Reissner, "Segmented cells as tool for development of fuel cells and error prevention/prediagnostic in fuel cell stacks," J. Power Sources, vol. 173, no. 1, pp. 19-27, 2007.

[49] M. Watanabe, H. Uchida, Y. Seki, M. Emori, and P. Stoneheart, "SelfHumidifying Polymer Electrolyte Membranes for Fuel Cells," J. Electrochem. Soc., vol. 143, no. 12, p. 3847, 1996.

[50] M. Watanabe, H. Uchida, and M. Emori, "Polymer Electrolyte Membranes Incorporated with Nanometer-Size Particles of Pt and / or Metal-Oxides: Experimental Analysis of the Self-Humidification and Suppression of GasCrossover in Fuel Cells," J. Phys. Chem. B, vol. 117, no. 97, pp. 3129-3137, 1998. 
[51] H. Hagihara, H. Uchida, and M. Watanabe, "Preparation of highly dispersed SiO2 and Pt particles in Nafion ${ }^{\circledR} 112$ for self-humidifying electrolyte membranes in fuel cells," Electrochim. Acta, vol. 51, no. 19, pp. 3979-3985, May 2006.

[52] X. Zhu, H. Zhang, Y. Zhang, Y. Liang, X. Wang, and B. Yi, “An ultrathin selfhumidifying membrane for PEM fuel cell application: fabrication, characterization, and experimental analysis.," J. Phys. Chem. B, vol. 110, no. 29, pp. 14240-8, Jul. 2006.

[53] K. T. Adjemian, S. Srinivasan, J. Benziger, and a. B. Bocarsly, "Investigation of PEMFC operation above $100{ }^{\circ} \mathrm{C}$ employing perfluorosulfonic acid silicon oxide composite membranes," J. Power Sources, vol. 109, no. 2, pp. 356-364, 2002.

[54] K. T. Adjemian, R. Dominey, L. Krishnan, H. Ota, P. Majsztrik, T. Zhang, J. Mann, B. Kirby, L. Gatto, M. Velo-Simpson, J. Leahy, S. Srimvasan, J. B. Benziger, and A. B. Bocarsly, "Function and characterization of metal oxidenafion composite membranes for elevated-temperature H 2/O 2 PEM fuel cells," Chem. Mater., vol. 18, no. 9, pp. 2238-2248, 2006.

[55] L. Wang, D. Zhao, H. M. Zhang, D. M. Xing, and B. L. Yi, "Water-Retention Effect of Composite Membranes with Different Types of Nanometer Silicon Dioxide," Electrochem. Solid-State Lett., vol. 11, no. 11, p. B201, 2008.

[56] L. Wang, D. M. Xing, Y. H. Liu, Y. H. Cai, Z. G. Shao, Y. F. Zhai, H. X. Zhong, B. L. Yi, and H. M. Zhang, "Pt/SiO2 catalyst as an addition to Nafion/PTFE selfhumidifying composite membrane,” J. Power Sources, vol. 161, no. 1, pp. 61-67, 2006.

[57] F. Pereira, K. Vallé, P. Belleville, A. Morin, S. Lamberts, and C. Sanchez, "Advanced mesostructured hybrid silica-nafion membranes for high-performance PEM fuel cell," Chem. Mater., vol. 20, no. 5, pp. 1710-1718, 2008.

[58] L. Ghassemzadeh, G. Pace, V. Di Noto, and K. Müller, "Effect of SiO2 on the dynamics of proton conducting [Nafion/(SiO2)X] composite membranes: a solidstate 19F NMR study.," Phys. Chem. Chem. Phys., vol. 13, no. 20, pp. 9327-9334, 2011.

[59] M. Schulze, T. Knöri, A. Schneider, and E. Gülzow, "Degradation of sealings for PEFC test cells during fuel cell operation," J. Power Sources, vol. 127, no. 1-2, pp. 222-229, Mar. 2004.

[60] S.-Y. Ahn, S.-J. Shin, H. Y. Ha, S. -a. Hong, Y.-C. Lee, T. W. Lim, and I.-H. Oh, "Performance and lifetime analysis of the kW-class PEMFC stack," J. Power Sources, vol. 106, no. 1-2, pp. 295-303, Apr. 2002. 
[61] J. Tan, Y. J. Chao, X. Li, and J. W. Van Zee, "Degradation of silicone rubber under compression in a simulated PEM fuel cell environment," J. Power Sources, vol. 172, no. 2, pp. 782-789, Oct. 2007.

[62] J. Tan, Y. J. Chao, M. Yang, C. T. Williams, and J. W. Van Zee, "Degradation Characteristics of Elastomeric Gasket Materials in a Simulated PEM Fuel Cell Environment," J. Mater. Eng. Perform., vol. 17, no. 6, pp. 785-792, Apr. 2008.

[63] S. Bhargava, K. A. O’Leary, T. C. Jackson, and B. Lakshmanan, "Durability testing of silicone materials for PEMFC use," Rubber Chem. Technol., vol. 86, no. 1, pp. 28-37, 2013.

[64] M. Schulze and C. Christenn, "XPS investigation of the PTFE induced hydrophobic properties of electrodes for low temperature fuel cells," Appl. Surf. Sci., vol. 252, no. 1 SPEC. ISS., pp. 148-153, 2005.

[65] G. Beamson and D. Briggs, High Resolution XPS of Organic Polymers: The Scienta ESCA 300 database. John Wiley \& Sons, 1992.

[66] C. Chen and T. F. Fuller, "The effect of humidity on the degradation of Nafion membrane," Polym. Degrad. Stab., vol. 94, no. 9, pp. 1436-1447, 2009.

[67] V. A. Sethuraman, J. W. Weidner, and L. V. Protsailo, "Effect of Diphenyl Siloxane on the Catalytic Activity of Pt on Carbon," Electrochem. Solid-State Lett., vol. 10, no. 12, p. B207, 2007.

[68] T. Okada, Y. Ayato, J. Dale, M. Yuasa, I. Sekine, and O. Andreas Asbjørnsen, "Oxygen reduction kinetics at platinum electrodes covered with perfluorinated ionomer in the presence of impurity cations Fe3+, Ni2+ and Cu2+," Phys. Chem. Chem. Phys., vol. 2, no. 14, pp. 3255-3261, 2000.

[69] T. Okada, Y. Ayato, H. Satou, M. Yuasa, and I. Sekine, "The effect of impurity cations on the oxygen reduction kinetics at platinum electrodes covered with perfluorinated ionomer," J. Phys. Chem. B, vol. 105, no. 29, pp. 6980-6986, 2001.

[70] J. Durst, M. Chatenet, and F. Maillard, "Impact of metal cations on the electrocatalytic properties of $\mathrm{Pt} / \mathrm{C}$ nanoparticles at multiple phase interfaces," Phys. Chem. Chem. Phys., vol. 14, no. 37, p. 13000, 2012.

[71] B. Kienitz, B. Pivovar, T. Zawodzinski, and F. H. Garzon, "Cationic Contamination Effects on Polymer Electrolyte Membrane Fuel Cell Performance," J. Electrochem. Soc., vol. 158, no. 9, p. B1175, 2011.

[72] T. Okada, Y. Ayato, M. Yuasa, and I. Sekine, "The Effect of Impurity Cations on the Transport Characteristics of Perfluorosulfonated Ionomer Membranes," J. Phys. Chem. B, vol. 103, no. 17, pp. 3315-3322, 1999. 
[73] B. S. Pivovar, B. Kienitz, T. Rockward, F. A. Uribe, and F. H. Garzon, "Performance impact of cationic contaminants," in Handbook of Fuel Cells: Advances in Electrocatalysis, Materials, Diagnostics and Durability, Vol. 6., W. Vielstich, H. Yokokawa, and H. A. Gasteiger, Eds. John Wiley \& Sons, 2009, pp. $718-727$.

[74] T. Okada, H. Satou, M. Okuno, and M. Yuasa, "Ion and water transport characteristics of perfluorosulfonated ionomer membranes with $\mathrm{H}+$ and alkali metal cations," J. Phys. Chem. B, vol. 106, no. 6, pp. 1267-1273, 2002.

[75] M. J. Kelly, G. Fafilek, J. O. Besenhard, H. Kronberger, and G. E. Nauer, "Contaminant absorption and conductivity in polymer electrolyte membranes," J. Power Sources, vol. 145, no. 2, pp. 249-252, 2005.

[76] M. Sulek, J. Adams, S. Kaberline, M. Ricketts, and J. R. Waldecker, "In situ metal ion contamination and the effects on proton exchange membrane fuel cell performance," J. Power Sources, vol. 196, no. 21, pp. 8967-8972, Nov. 2011.

[77] R. Baldwin, M. Pham, A. Leonida, J. McElroy, and T. Nalette, "Hydrogen-Oxygen Proton-Exchange Membrane Fuel Cells And Electrolyzers," NASA/TM N90-20467, 1989.

[78] D. E. Curtin, R. D. Lousenberg, T. J. Henry, P. C. Tangeman, and M. E. Tisack, "Advanced materials for improved PEMFC performance and life," J. Power Sources, vol. 131, no. 1-2, pp. 41-48, May 2004.

[79] F. A. De Bruijn, V. A. T. Dam, and G. J. M. Janssen, "Review: Durability and degradation issues of PEM fuel cell components," Fuel Cells, vol. 8, no. 1, pp. 3 22, 2008.

[80] M. Schulze, M. Lorenz, N. Wagner, and E. Gülzow, "XPS analysis of the degradation of Nafion," Fresenius J Anal Chem, vol. 365, pp. 106-113, 1999.

[81] D. T. Clark, W. J. Feast, D. Kilcast, and W. K. R. Musgrave, "Applications of ESCA to Polymer Chemistry," J. Polym. Sci., vol. 11, pp. 389-411, 1973. 
Table 1

\begin{tabular}{ll}
\hline Cell Temperature & $60{ }^{\circ} \mathrm{C}$ (durability test) \\
& $80{ }^{\circ} \mathrm{C}$ (characterization) \\
Reactant pressure & $1.5 \mathrm{bar}$ \\
Total current & $100 \mathrm{~A}$, i.e. $0.7 \mathrm{~A} \mathrm{~cm}$ (durability test) $^{-2}$ \\
Gas flow rate & Anode $\left(\mathrm{H}_{2}\right): 840 \mathrm{ml} \mathrm{min}^{-1}$ \\
& Cathode (Air): $3320 \mathrm{ml} \mathrm{min}^{-1}$ \\
Relative humidity & $5 \% / 5 \%$ or $100 \% / 100 \%$ (durability test) \\
& $50 \% / 50 \%$ (characterization) \\
Segments location & Anode inlet: A1, B1, C1 \\
& Anode outlet: $\mathrm{G} 10, \mathrm{H} 10, \mathrm{I} 10$ \\
& Cathode inlet: G1, H1, I1 \\
& Cathode outlet: A10, B10, C10
\end{tabular}

Table 2

\begin{tabular}{|c|c|c|c|c|c|c|c|c|c|c|c|c|}
\hline \multirow[b]{2}{*}{ Segment } & \multicolumn{5}{|c|}{$\mathrm{Ni} / \mathrm{wt} \%$} & \multicolumn{5}{|c|}{$\mathrm{Si} / \mathrm{wt} \%$} & \multicolumn{2}{|c|}{$P t / w t \%$} \\
\hline & An-M & PTFE & Ca-M & An & $\mathbf{C a}$ & An-M & PTFE & Ca-M & An & $\mathbf{C a}$ & PTFE & Ca-M \\
\hline $\mathrm{C} 2$ & $\begin{array}{c}3.4 \pm \\
2.9\end{array}$ & $\begin{array}{c}2.6 \pm \\
2.3\end{array}$ & $\begin{array}{c}3.6 \pm \\
3.2\end{array}$ & - & $\begin{array}{c}0.5 \pm \\
0.9\end{array}$ & $\begin{array}{c}2.3 \pm \\
0.7\end{array}$ & $\begin{array}{c}0.3 \pm \\
0.1\end{array}$ & $\begin{array}{c}1.5 \pm \\
0.7\end{array}$ & $\begin{array}{c}1.1 \pm \\
0.5\end{array}$ & - & $\begin{array}{c}0.4 \pm \\
0.4\end{array}$ & $\begin{array}{c}0.2 \pm \\
0.2\end{array}$ \\
\hline D5 & $\begin{array}{c}0.1 \pm \\
0.1\end{array}$ & $<0.1$ & $\begin{array}{c}0.2 \pm \\
0.2\end{array}$ & - & - & $\begin{array}{c}2.2 \pm \\
0.5\end{array}$ & $\begin{array}{c}0.3 \pm \\
0.3\end{array}$ & $\begin{array}{c}1.4 \pm \\
0.6\end{array}$ & - & $\begin{array}{c}0.3 \pm \\
0.5\end{array}$ & $\begin{array}{c}0.7 \pm \\
0.6\end{array}$ & $\begin{array}{c}0.1 \pm \\
0.1\end{array}$ \\
\hline H5 & - & - & - & - & - & $\begin{array}{c}0.6 \pm \\
0.2\end{array}$ & $\begin{array}{c}0.1 \pm \\
0.1\end{array}$ & $\begin{array}{c}0.7 \pm \\
0.2\end{array}$ & - & $\begin{array}{c}0.5 \pm \\
0.2\end{array}$ & $<0.1$ & $\begin{array}{c}0.3 \pm \\
0.1\end{array}$ \\
\hline I5 & - & $\begin{array}{c}0.2 \pm \\
0.2\end{array}$ & $<0.1$ & - & - & $\begin{array}{c}3.2 \pm \\
0.6\end{array}$ & $<0.1$ & $\begin{array}{c}2.3 \pm \\
0.5\end{array}$ & $\begin{array}{c}1.4 \pm \\
0.8\end{array}$ & $\begin{array}{c}1.2 \pm \\
0.6\end{array}$ & - & $\begin{array}{c}0.2 \pm \\
0.4\end{array}$ \\
\hline E10 & $\begin{array}{c}2.9 \pm \\
0.4\end{array}$ & $\begin{array}{c}1.8 \pm \\
0.9\end{array}$ & $\begin{array}{l}2.8 \pm \\
0.3\end{array}$ & $\begin{array}{c}0.5 \pm \\
0.2\end{array}$ & $\begin{array}{c}0.2 \pm \\
0.2\end{array}$ & $\begin{array}{c}2.7 \pm \\
0.6\end{array}$ & $\begin{array}{c}0.2 \pm \\
0.1\end{array}$ & $\begin{array}{c}2.6 \pm \\
0.0\end{array}$ & $\begin{array}{c}0.8 \pm \\
0.4\end{array}$ & $\begin{array}{c}1.9 \pm \\
0.3\end{array}$ & - & $\begin{array}{c}0.2 \pm \\
0.3\end{array}$ \\
\hline $\mathrm{H} 10$ & - & - & - & - & - & $\begin{array}{c}2.4 \pm \\
0.5\end{array}$ & $\begin{array}{c}0.3 \pm \\
0.3\end{array}$ & $\begin{array}{c}1.9 \pm \\
0.2\end{array}$ & $\begin{array}{c}1.2 \pm \\
1.1\end{array}$ & $\begin{array}{c}2.4 \pm \\
1.3\end{array}$ & $\begin{array}{c}0.1 \pm \\
0.2\end{array}$ & - \\
\hline $\begin{array}{c}\text { Pristine } \\
\text { MEA }\end{array}$ & - & - & - & - & - & $\begin{array}{c}2.0 \pm \\
0.7\end{array}$ & $\begin{array}{c}0.1 \pm \\
0.1\end{array}$ & $\begin{array}{c}1.5 \pm \\
0.6\end{array}$ & - & - & - & - \\
\hline
\end{tabular}


Table 3

\begin{tabular}{|c|c|c|c|c|c|c|c|c|c|c|c|c|}
\hline \multirow[b]{2}{*}{ Segment } & \multicolumn{5}{|c|}{$\mathrm{Ni} / \mathrm{wt} \%$} & \multicolumn{5}{|c|}{$\mathrm{Si} / w t \%$} & \multicolumn{2}{|c|}{$P t / w t \%$} \\
\hline & An-M & PTFE & Ca-M & An & $\mathbf{C a}$ & An-M & PTFE & Ca-M & An & $\mathrm{Ca}$ & PTFE & Ca-M \\
\hline $\mathrm{C} 2$ & $\begin{array}{c}1.4 \pm \\
0.2\end{array}$ & $\begin{array}{c}0.4 \pm \\
0.3\end{array}$ & $\begin{array}{c}2.4 \pm \\
0.0\end{array}$ & - & - & $\begin{array}{c}3.8 \pm \\
1.2\end{array}$ & $\begin{array}{c}0.3 \pm \\
0.2\end{array}$ & $\begin{array}{c}1.8 \pm \\
0.4\end{array}$ & - & $\begin{array}{c}0.2 \pm \\
0.3\end{array}$ & $\begin{array}{c}0.6 \pm \\
0.6\end{array}$ & - \\
\hline F5 & - & - & - & - & - & $\begin{array}{c}1.9 \pm \\
0.3\end{array}$ & $\begin{array}{c}0.2 \pm \\
0.1\end{array}$ & $\begin{array}{c}1.9 \pm \\
0.4\end{array}$ & - & - & - & - \\
\hline I5 & - & - & - & - & - & $\begin{array}{c}2.2 \pm \\
0.0\end{array}$ & $<0.1$ & $\begin{array}{c}2.0 \pm \\
0.8\end{array}$ & $\begin{array}{c}< \\
0.1\end{array}$ & $\begin{array}{c}0.6 \pm \\
0.9\end{array}$ & $\begin{array}{c}0.3 \pm \\
0.4\end{array}$ & $\begin{array}{c}0.2 \pm \\
0.4\end{array}$ \\
\hline E10 & $\begin{array}{c}5.5 \pm \\
0.6\end{array}$ & $\begin{array}{l}3.2 \pm \\
0.5\end{array}$ & $\begin{array}{c}5.0 \pm \\
0.5\end{array}$ & $\begin{array}{c}0.8 \pm \\
0.8\end{array}$ & $\begin{array}{c}< \\
0.1\end{array}$ & $\begin{array}{c}2.3 \pm \\
0.3\end{array}$ & $<0.1$ & $\begin{array}{c}2.5 \pm \\
0.4\end{array}$ & - & - & $<0.1$ & - \\
\hline H10 & $\begin{array}{l}1.9 \pm \\
0.3\end{array}$ & $\begin{array}{c}0.4 \pm \\
0.2\end{array}$ & $\begin{array}{c}1.2 \pm \\
0.4\end{array}$ & $<0.1$ & $\begin{array}{c}< \\
0.1\end{array}$ & $\begin{array}{l}1.3 \pm \\
0.5\end{array}$ & - & $\begin{array}{c}2.1 \pm \\
0.2\end{array}$ & $<$ & $<0.1$ & $\begin{array}{c}0.2 \pm \\
0.3\end{array}$ & $\begin{array}{c}0.1 \pm \\
0.2\end{array}$ \\
\hline $\begin{array}{c}\text { Pristine } \\
\text { MEA }\end{array}$ & - & - & - & - & - & $\begin{array}{c}2.0 \pm \\
0.7\end{array}$ & $\begin{array}{c}0.1 \pm \\
0.1\end{array}$ & $\begin{array}{c}1.5 \pm \\
0.6\end{array}$ & - & - & - & - \\
\hline
\end{tabular}


a) $A$ B C D E F G H ।

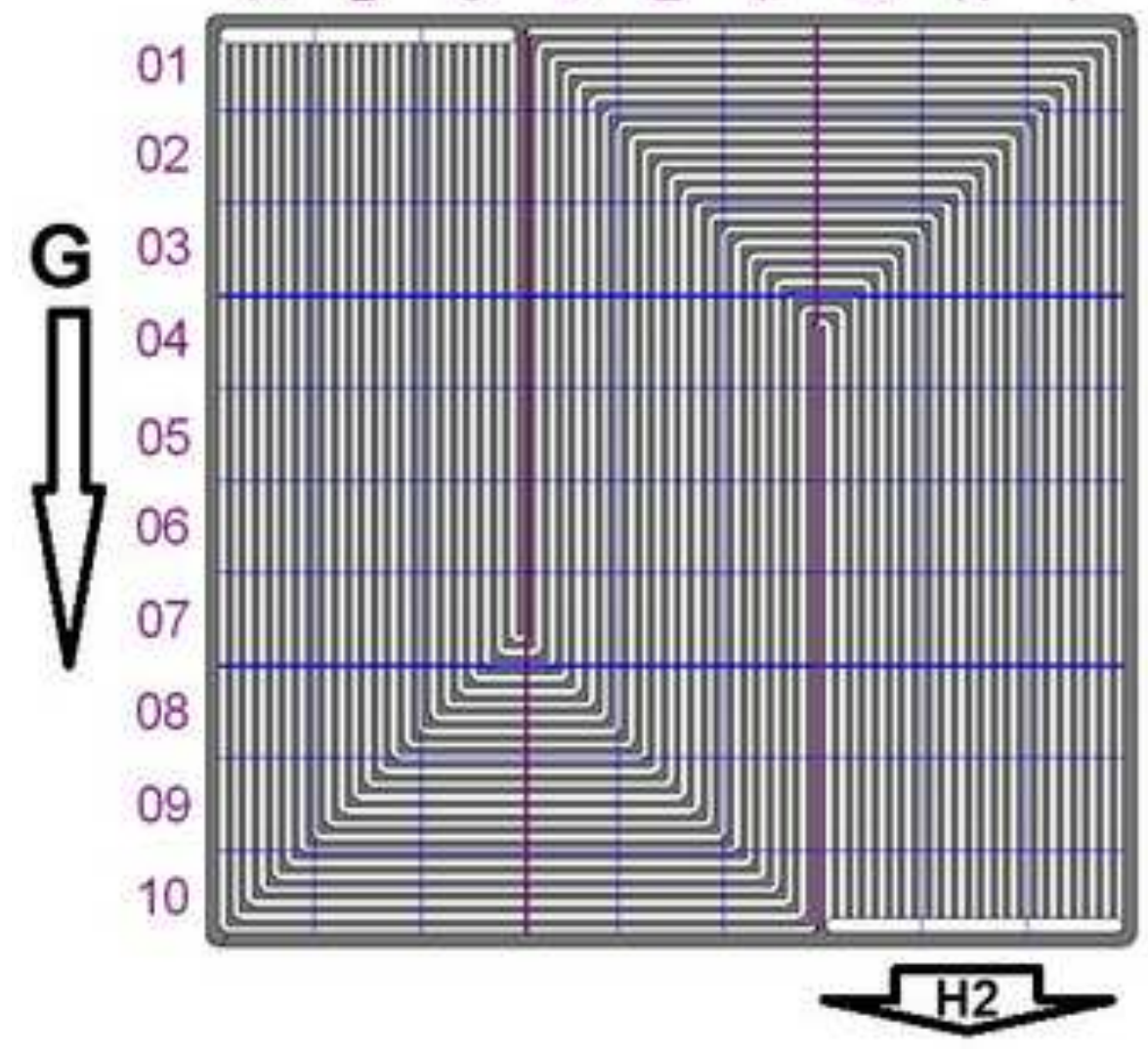

b) CATHODE

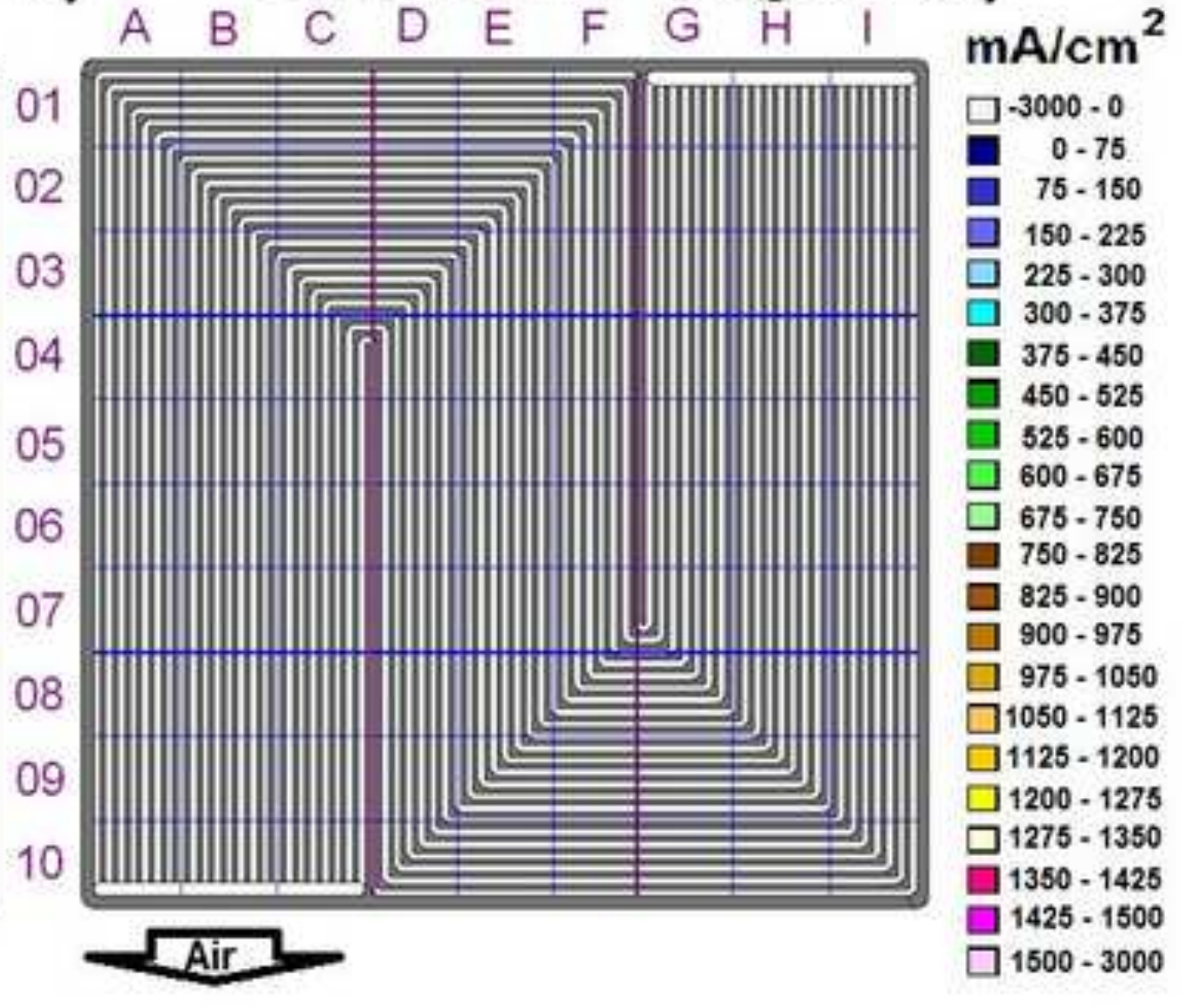


Click here to download high resolution image

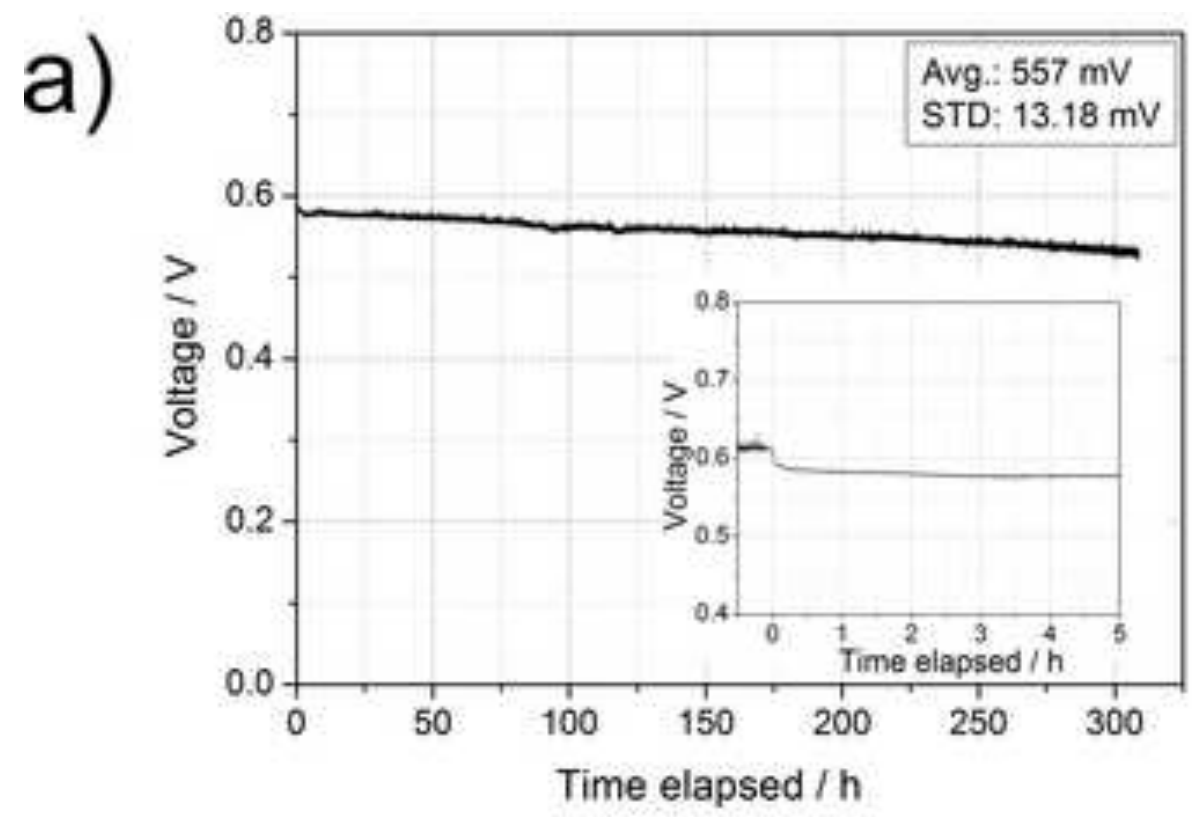

b)BoT

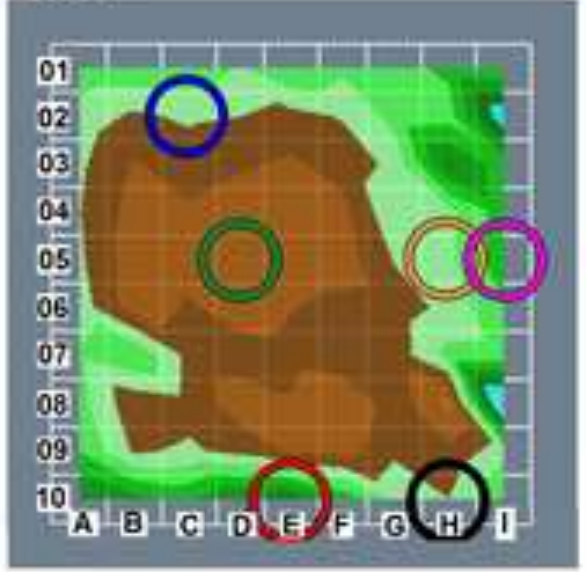

EoT

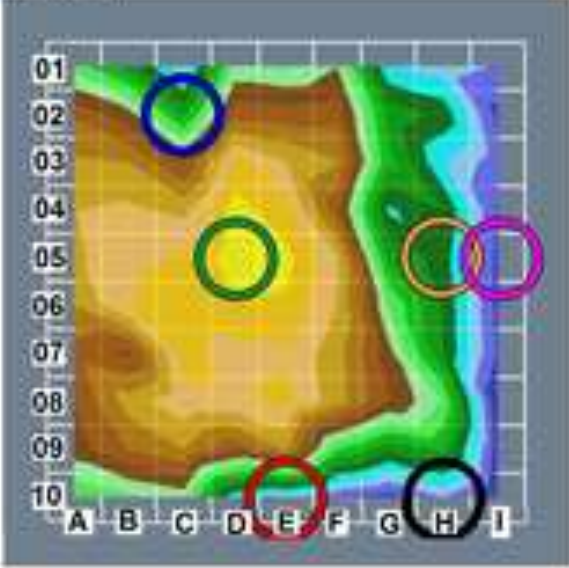

c)
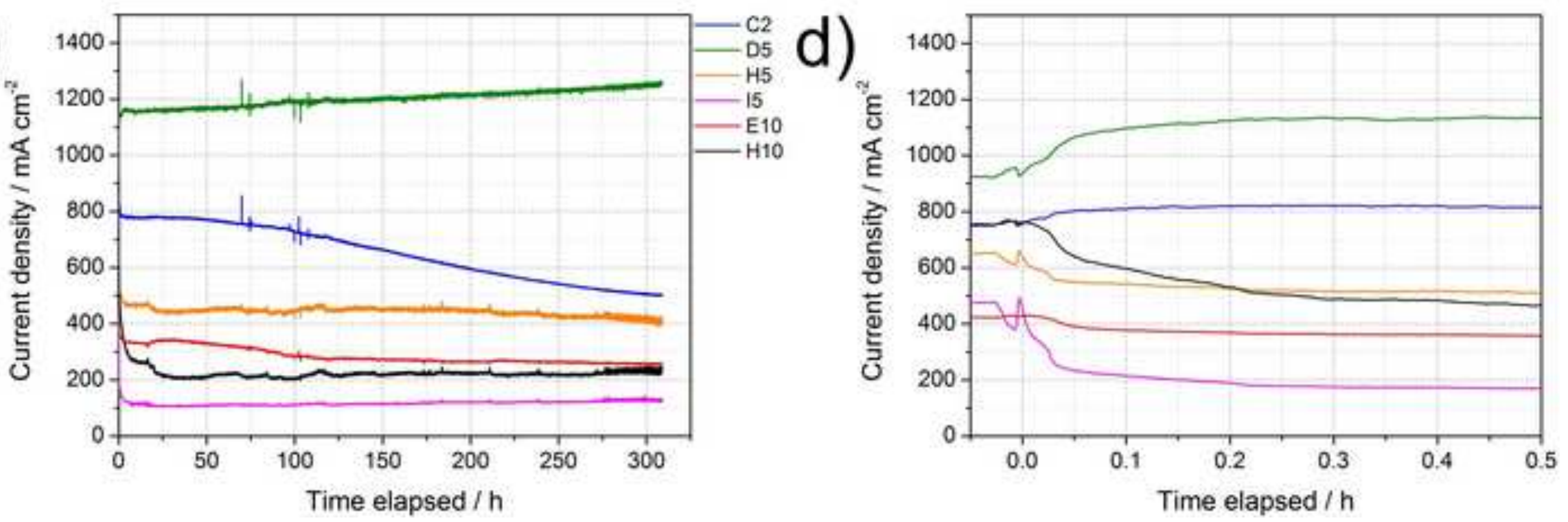


\section{Figure}

Click here to download high resolution image
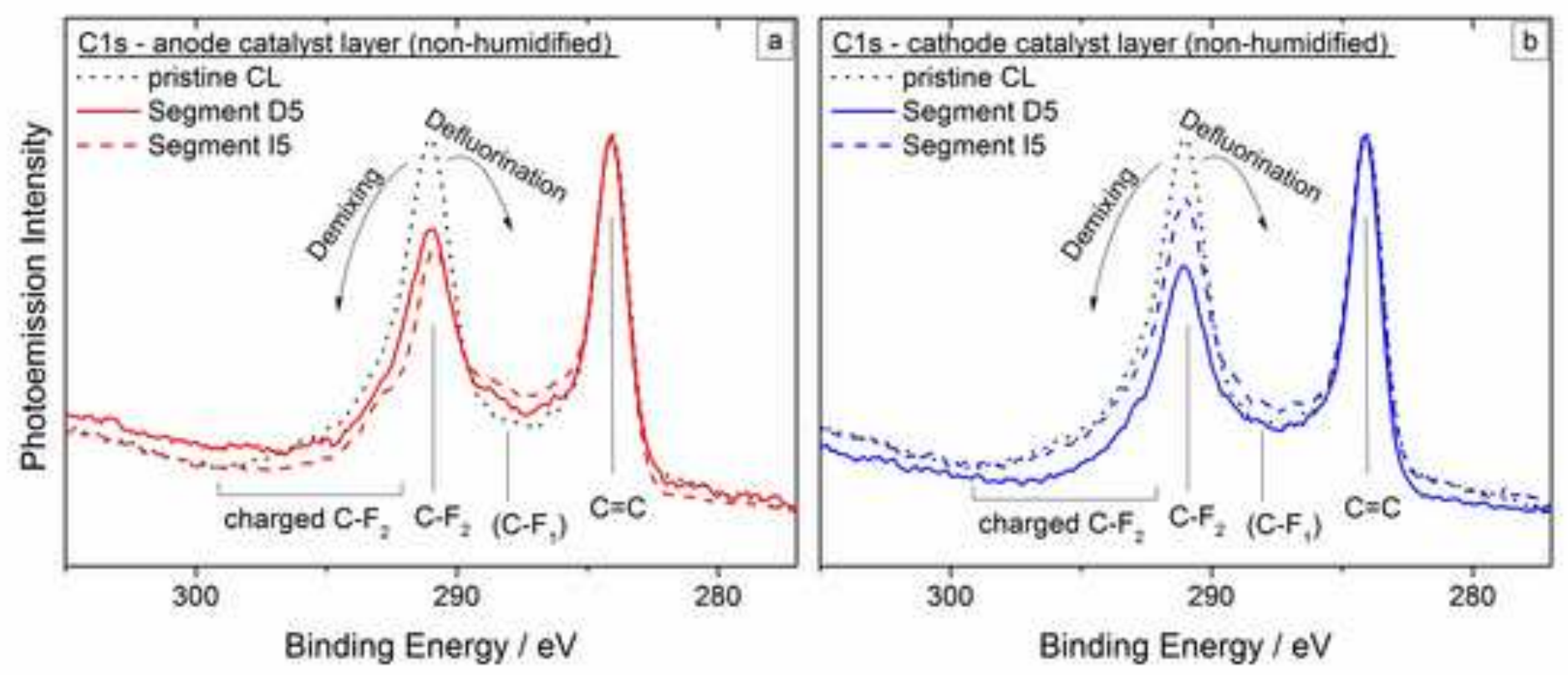
Click here to download high resolution image

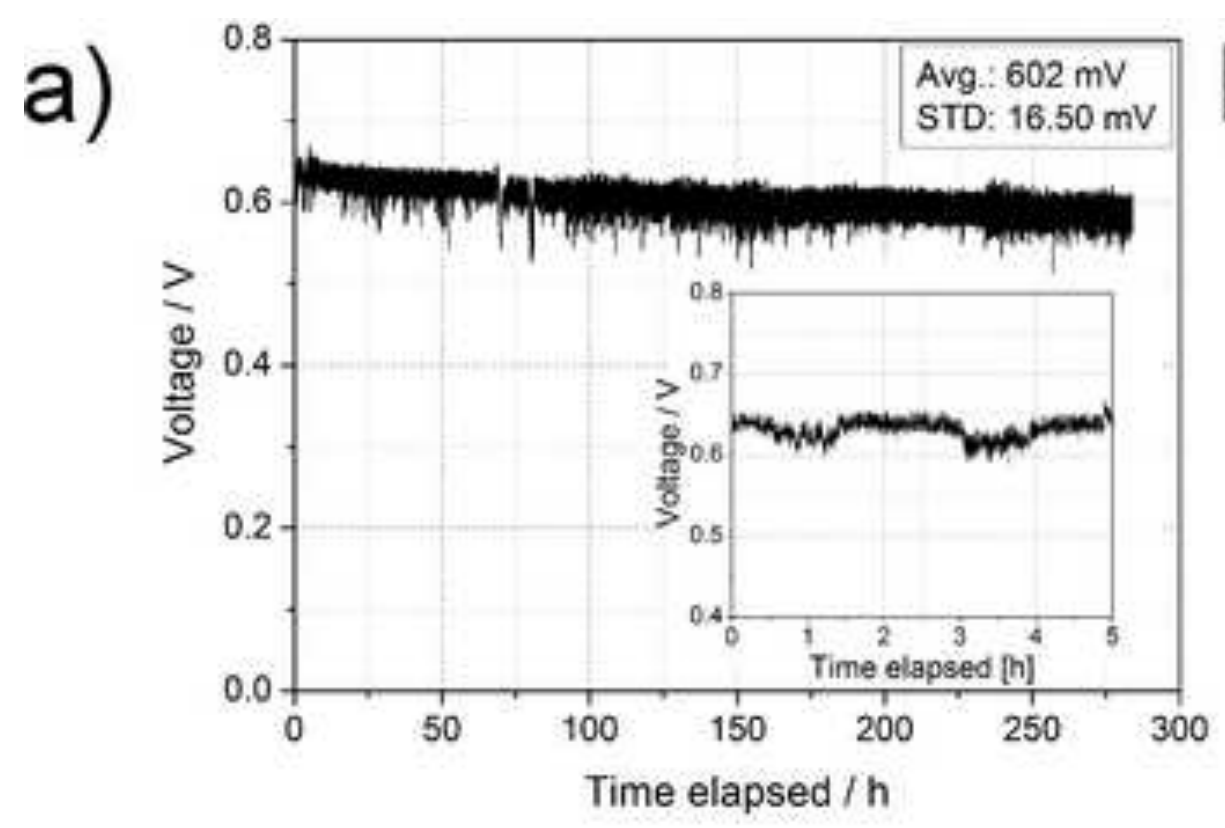

b)BoT

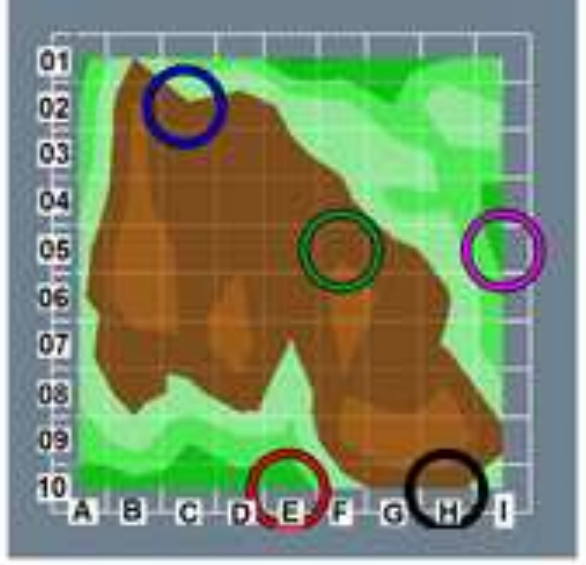

EoT

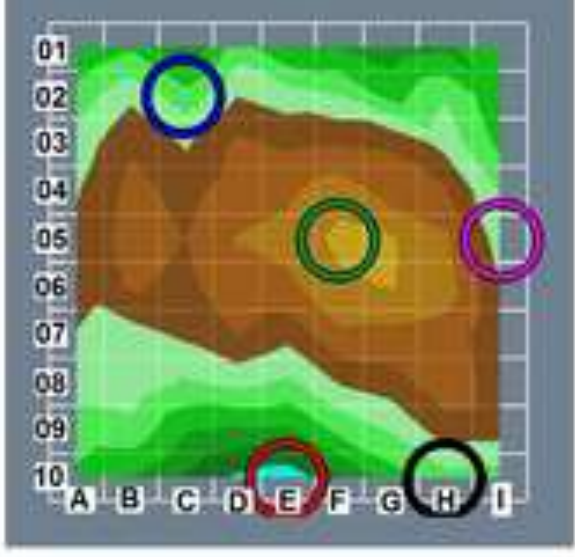

c)
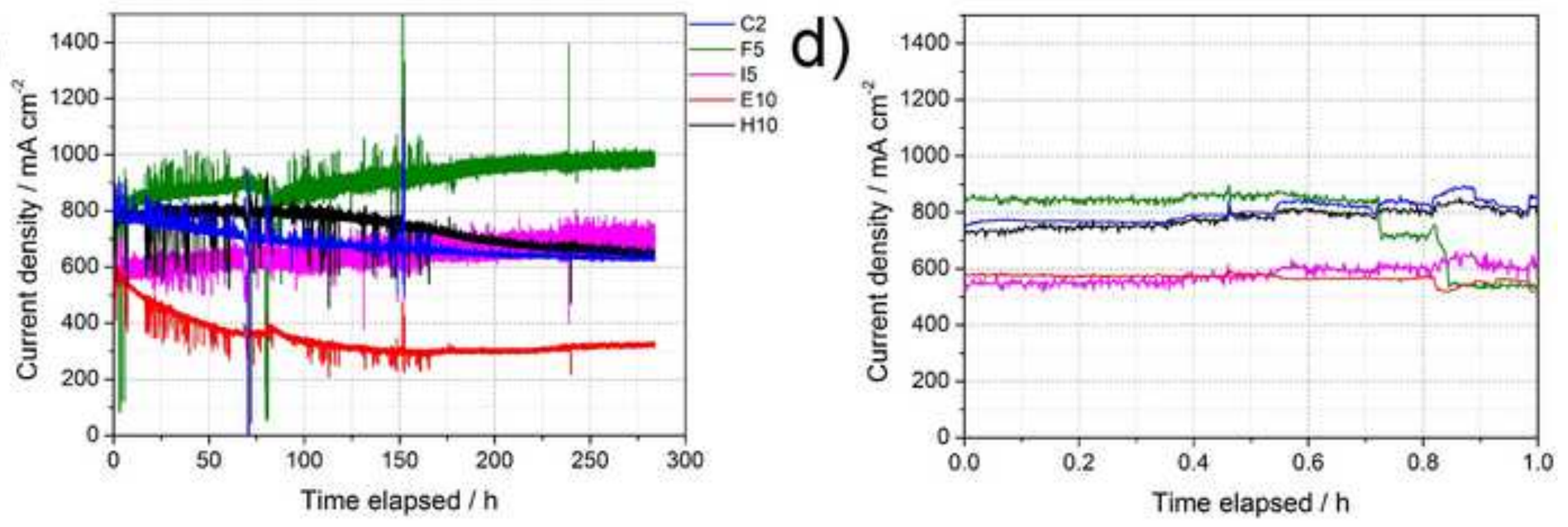


\section{Figure 5}

Click here to download high resolution image
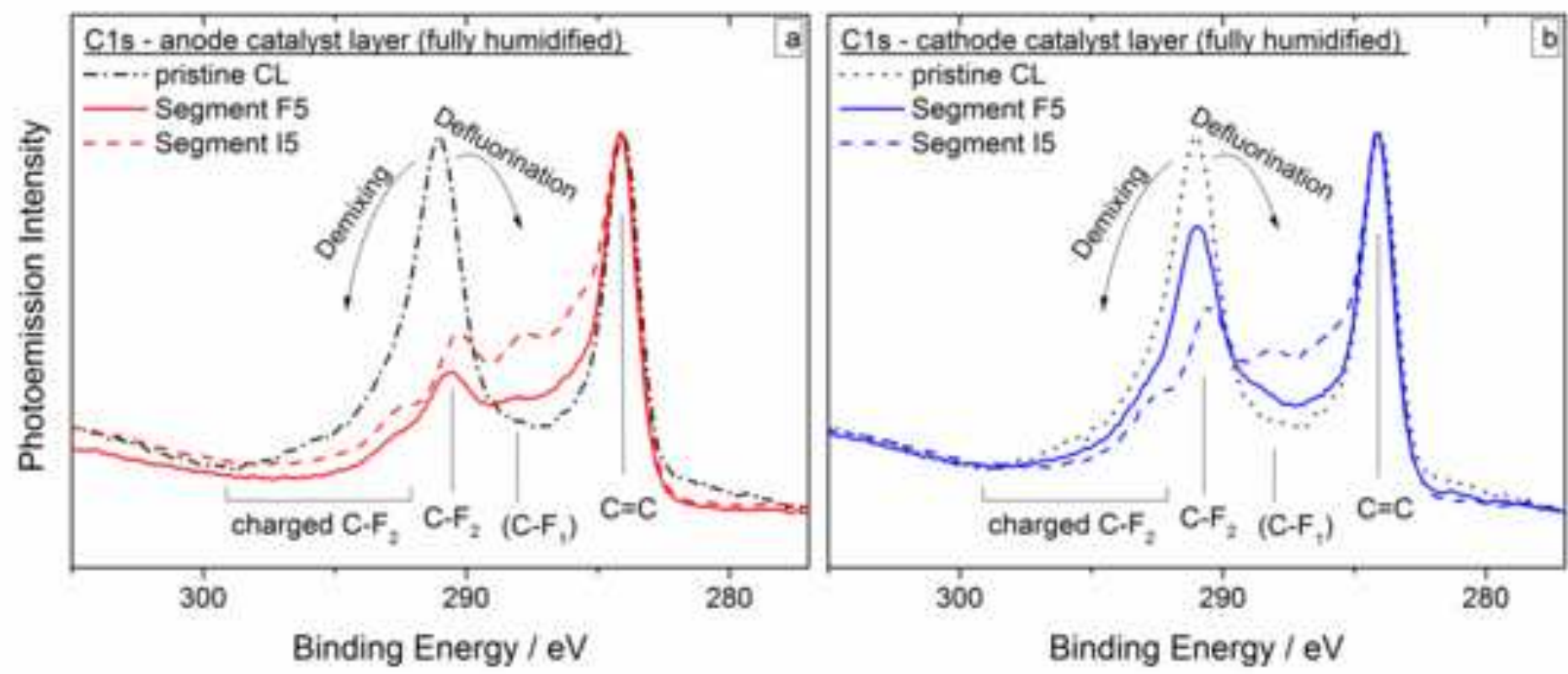

Binding Energy / eV

Binding Energy / eV 
during durability test@ 5 \% RH

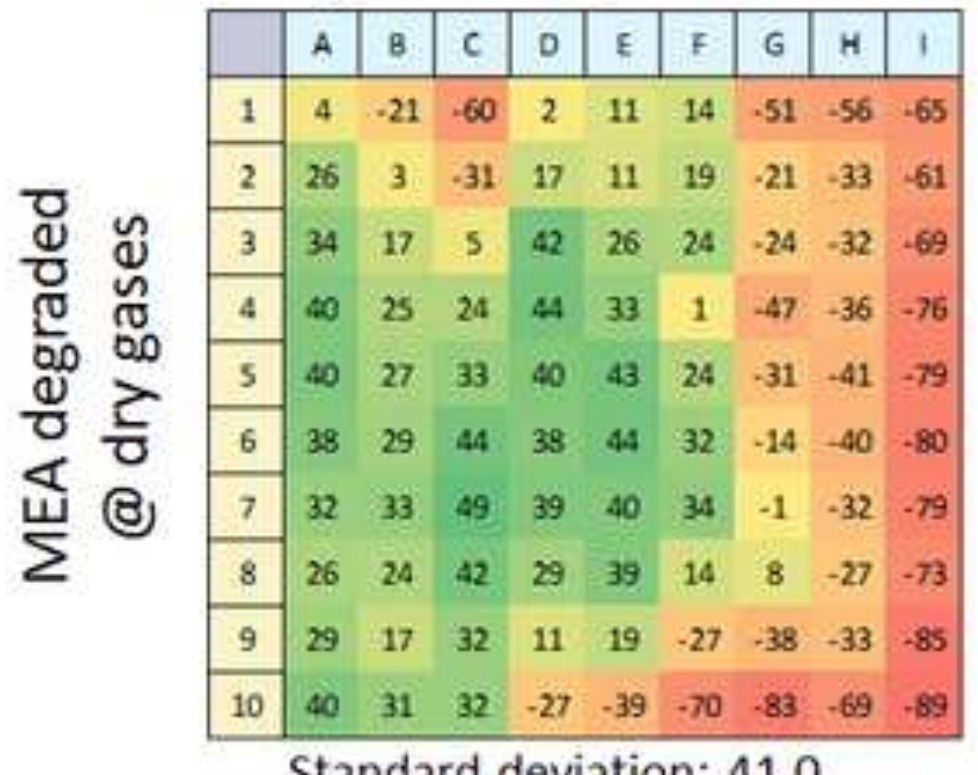

Standard deviation: 41.0

during durability test @ 100 \% RH

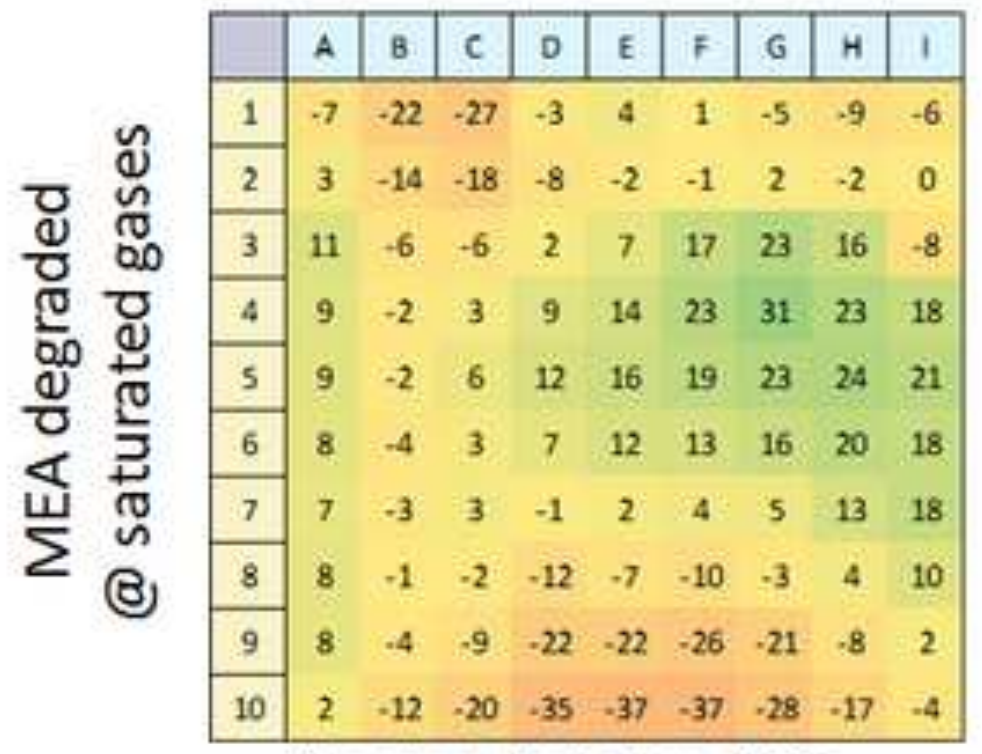

Standard deviation: 14.6 in E-j curves@ $90 \%$ RH

\begin{tabular}{|c|c|c|c|c|c|c|c|c|c|}
\hline & A & B & C & D & $E$ & F & G & H & 1 \\
\hline 1 & 7 & .26 & -66 & -20 & -16 & -18 & -67 & -49 & .40 \\
\hline 2 & 16 & -4 & -43 & 3 & 0 & 3 & .40 & -31 & -39 \\
\hline 3 & 24 & 10 & -3 & 25 & 16 & 21 & -20 & -16 & -32 \\
\hline 4 & 31 & is & 18 & 27 & 24 & 6 & -22 & -21 & -30 \\
\hline 5 & 30 & 16 & 23 & 25 & 33 & 19 & -17 & -25 & -32 \\
\hline 6 & 31 & 17 & 26 & 25 & 38 & 18 & -14 & -24 & -34 \\
\hline 7 & 27 & 16 & 27 & 24 & 32 & 21 & -12 & -23 & -34 \\
\hline 8 & 21 & 15 & 25 & 19 & 40 & 9 & -11 & -24 & 14 \\
\hline 9 & 20 & 10 & 18 & 5 & 19 & -14 & -26 & -24 & -38 \\
\hline 10 & 37 & 29 & 23 & -22 & -23 & -37 & -42 & -33 & -40 \\
\hline
\end{tabular}

Standard deviation: 26.8

in E-j curves @ 50 \% RH

\begin{tabular}{|c|c|c|c|c|c|c|c|c|c|}
\hline & A & B & $c$ & 0 & $E$ & $F$ & G & $H$ & 1 \\
\hline 1 & -11 & -21 & -30 & 1 & 6 & -5 & -27 & -33 & -29 \\
\hline 2 & 0 & -8 & -17 & 2 & 5 & 1 & -16 & -24 & 0 \\
\hline 3 & 9 & 2 & 1 & 14 & 17 & 17 & 14 & 0 & -23 \\
\hline 4 & 11 & 6 & 16 & 26 & 25 & 26 & 25 & 20 & 6 \\
\hline 5 & 14 & 8 & 20 & 27 & 28 & 25 & 28 & 26 & 17 \\
\hline 6 & 15 & 6 & 14 & 18 & 22 & 16 & 24 & 29 & 25 \\
\hline 7 & 7 & -1 & 4 & 3 & 5 & 6 & 11 & 20 & 28 \\
\hline 8 & 4 & -2 & -5 & -13 & -13 & -14 & -5 & 6 & 17 \\
\hline 9 & 3 & -7 & -14 & -30 & -37 & -38 & -32 & -16 & -2 \\
\hline 10 & 0 & -10 & -24 & -48 & .56 & .57 & -46 & -31 & -7 \\
\hline
\end{tabular}

Standard deviation: 20.7

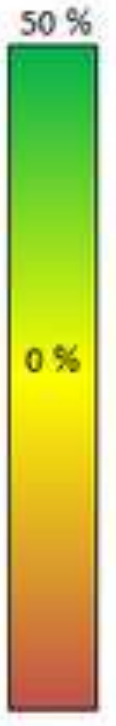

$-100 \%$ 


\section{Figure 7}

Click here to download high resolution image

a)

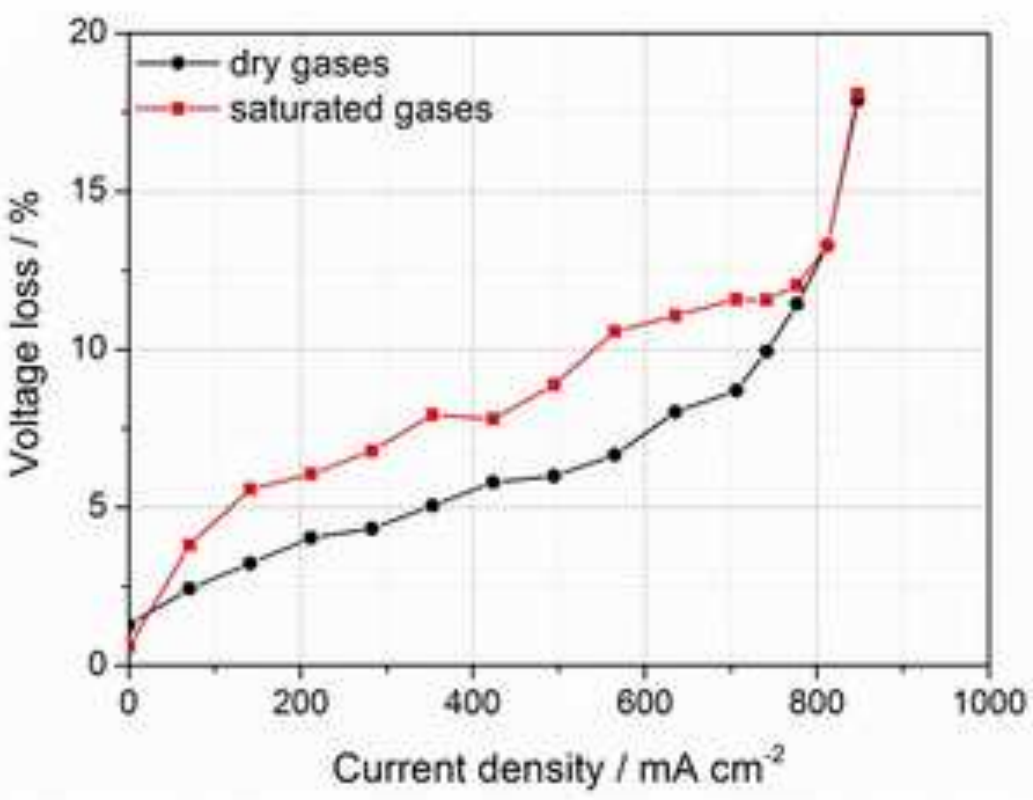

b)

\begin{tabular}{|c|c|c|c|c|c|c|c|c|c|c|c|c|c|c|c|c|c|c|c|c|c|c|c|c|c|c|c|c|c|c|}
\hline & \multicolumn{10}{|c|}{ (9) $70 \mathrm{~mA} \mathrm{~cm}^{2}$} & \multicolumn{10}{|c|}{ (4) $495 \mathrm{~mA} \mathrm{~cm}^{-2}$} & & \multicolumn{9}{|c|}{ (9) $775 \mathrm{~mA} \mathrm{~cm}^{-2}$} \\
\hline \multirow{11}{*}{$\begin{array}{l}0 \\
0 \\
0 \\
0 \\
0 \\
\frac{2}{0} \\
\text { (3) }\end{array}$} & & A & B & c. & D & $\mathrm{E}$ & 1 & 0 & $H$ & 1 & & $A$ & a & c & 0 & e & 1 & $\theta$ & $\mathrm{H}$ & 1 & & $A$ & 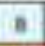 & c & D & $t$ & 1 & 0 & $\mathrm{H}$ & 1 \\
\hline & 1 & 4 & 45 & 24 & -41 & -10 & 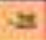 & 10 & -11 & .II & 1 & 0 & 46 & 6 & $\mathrm{z}$ & 21 & 24 & $n z$ & sis & 4 & 1 & 1 & $D$ & 4 & 24 & 15 & 22 & 40 & 44 & -13 \\
\hline & 2 & 20 & +2 & 15 & -12 & 43 & $\mathrm{nI}$ & $\mathbf{x}$ & $-3 x$ & ats & 2. & 11 & 40 & $\approx$ & 4 & 1 & 1 & -4t & in & $-4 t$ & 2 & 15 & $-t$ & at & 7 & 9 & 4 & ar & 46 & $\Leftrightarrow$ \\
\hline & 3 & 25 & 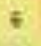 & 16 & 6 & 0 & 12 & 24 & 0 & -2 & 3 & 24 & 6 & 4 & $\mathbf{x}$ & 17 & $n$ & 26 & at & -5 & 3 & 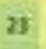 & 5 & 41 & $x$ & 4 & $\boldsymbol{D}$ & 2 & 4 & 2 \\
\hline & 4 & 20 & 12 & 4 & 7 & $\boldsymbol{p}$ & 2 & $\infty$ & 2 & $z$ & 4 & 10 & D & a & $\mathbf{z}$ & 25 & 6 & -25 & $n$ & $\Rightarrow$ & 4 & 27 & 10 & 6 & $n$ & a & 0 & $-2 x$ & 3 & I \\
\hline & 5 & $\Delta$ & 11 & 16 & s) & a & $n$ & 2 & 2 & 6 & 5 & 11 & is & $x$ & zi & 11 & in & 47 & 22 & -12 & 5 & 27 & 11 & 11 & nI & $x$ & 4 & 4 & 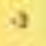 & 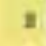 \\
\hline & 6 & II & $\mathrm{n}$ & is & 3 & A & n & 7 & 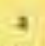 & 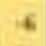 & 6 & 3 & 19 & $\mathrm{~s}$ & $n$ & $n$ & 16 & 22 & 22 & $-x$ & $E$ & 30 & a & 36 & $\mathrm{n}$ & 26 & a & 6 & 4 & 2 \\
\hline & 3 & 30 & is & 12 & 2 & $x$ & H & it & 6 & 4 & 7 & u & $\boldsymbol{n}$ & 8 & $n$ & 10 & 20 & tis & $-a$ & 3 & 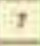 & 30 & is & 36 & v & $x$ & 1) & 4 & 2 & 0 \\
\hline & 1 & $x$ & 45 & a. & 6 & $z$ & 1 & 3 & 4 & 4 & 1 & 10 & 2 & $\mathbf{x}$ & $\mathbf{x}$ & pu & I & 9 & $n$ & 34 & 3 & 25 & $\mu$ & 13 & 3 & 26 & 5 & 4 & -1 & 7 \\
\hline & 5 & $y$ & 3 & -1 & 41 & 0 & - & -10 & 2 & $\cdot D$ & 3 & 29 & 13 & D & 4 & is & If & 24 & -94 & -41 & 3 & 4 & 3 & $b$ & .0 & 6 & D) & -4 & 0 & -6 \\
\hline & 10 & w7 & 5 & 45 & 42 & -34 & -4 & -3t & -5 & $2 z$ & 10 & $u$ & $z$ & 24 & 2 & 5 & 42 & 47 & ss. & -43 & 10 & $n$ & 12 & 2 & -36 & 20 & -3 & at & 9 & -12 \\
\hline
\end{tabular}

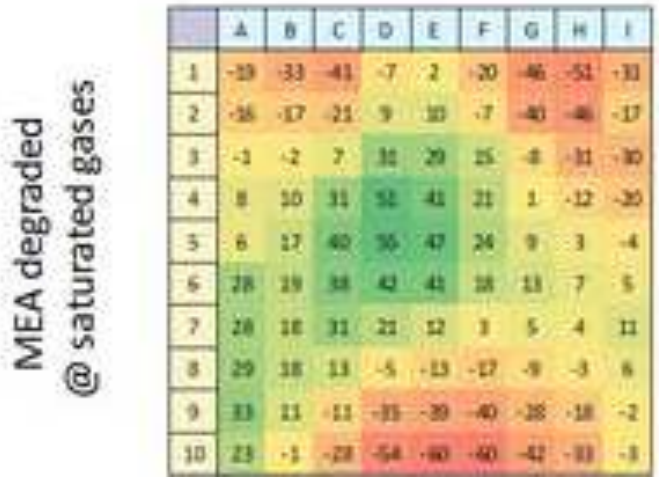

\begin{tabular}{|c|c|c|c|c|c|c|c|c|c|}
\hline & A & 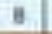 & c & D & $\varepsilon$ & $F$ & $\sigma$ & $\boldsymbol{H}$ & 1 \\
\hline 1 & 12 & $x$ & 36 & 2 & S & 7 & 29 & 36 & H \\
\hline 2 & -3 & 11 & $n$ & 3 & s! & 1 & 21 & 30 & 0 \\
\hline 1 & 12 & 3 & 4 & ta & 1t & 16 & 7 & $A$ & 42 \\
\hline 4 & 13 & H & It & $z$ & $n$ & as & 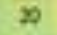 & s & 4 \\
\hline 5. & as & $a$ & $\boldsymbol{z}$ & $\mathrm{n}$ & $n$ & as & $n$ & $x$ & dr \\
\hline 6 & 24 & 4 & 13 & $x$ & $\pi i$ & is & 8 & $\mathbf{x}$ & $\mathrm{s}$ \\
\hline 7 & 19 & 9 & मI & 3 & 0. & 4 & 10 & zt & $z$ \\
\hline 2 & is & 3 & -3 & - ts & -22 & 15 & -8 & 4 & It \\
\hline 9 & 15 & 2 & -17 & $\infty$ & -1 & 4 & os & -92 & 2 \\
\hline 10 & 6 & $\rightarrow$ & 18 & 4 & e & 4 & 4 & +4 & -3 \\
\hline
\end{tabular}

\begin{tabular}{|c|c|c|c|c|c|c|c|c|c|}
\hline & 4 & 3 & c & 0 & $E$ & $F$ & 6 & $H$ & 1 \\
\hline 1 & 4 & $\infty 2$ & 10 & 3 & 5 & 4 & 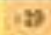 & 8 & -2 \\
\hline 2 & 4 & u & 17 & 0 & 5 & 4 & -12 & 22 & 0 \\
\hline 1 & 7 & 2 & 2 & 17 & $D$ & x & 5 & -48 & -2 \\
\hline 4 & 19 & 12 & is & $D$ & 22 & $\boldsymbol{x}$ & II & 7 & $-y$ \\
\hline 5 & 25 & 36 & 24 & 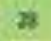 & $\boldsymbol{z}$ & $\mathbf{a}$ & $B$ & $\mathbf{p}$ & 5 \\
\hline 6 & 10 & $\pi$ & $u$ & 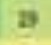 & $\mathbf{a}$ & $u$ & Bs & 12 & $\mathrm{~b}$ \\
\hline 7 & In & 9 & 12 & 5 & 4 & 1 & 6 & $\mathbf{z}$ & 19 \\
\hline$t$ & 12 & 2 & $\rightarrow$ & a & -12 & -14 & s & 3 & is \\
\hline 9 & 1 & $\Rightarrow$ & 41 & $n$ & n & -35 & $\mathbf{2}$ & , n & 1 \\
\hline 10 & 2 & $-1 \mathrm{I}$ & 24 & 4 & $+\infty$ & $\&$ & 44 & -2 & -6 \\
\hline
\end{tabular}




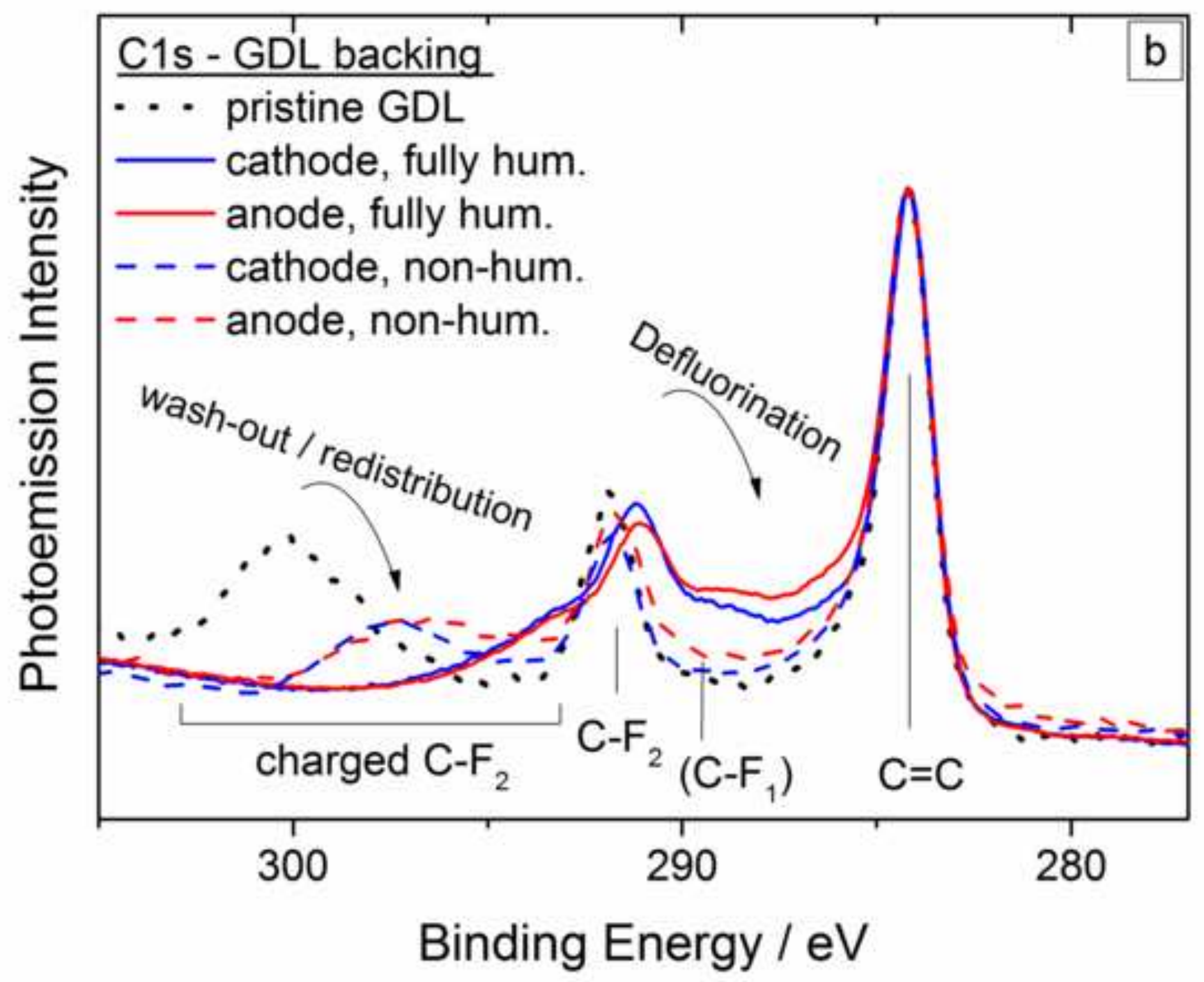




\section{Captions}

\section{Tables}

\section{Table 1}

Operating conditions and location of segments at anode/cathode inlet and outlet

\section{Table 2}

Result of the quantitatively analyzed EDX spectra for $\mathrm{Ni}, \mathrm{Si}$, and Pt in the MEA operated under non-humidified gas supply. Given values are averaged from at least three measured values. An-M and $\mathrm{Ca}-\mathrm{M}$ indicate analysis results of membrane samples at the anode and cathode side, respectively; PTFE indicates the membrane PTFE-reinforcement layer; An and Ca refer to analysis of anode and cathode catalyst layer, respectively.

\section{Table 3}

Result of the quantitatively analyzed EDX spectra for $\mathrm{Ni}, \mathrm{Si}$, and $\mathrm{Pt}$ in the MEA operated at fully humidified conditions. Given values are averaged from at least three measured values. An-M and $\mathrm{Ca}-\mathrm{M}$ indicate analysis of membrane samples the anode and cathode side, respectively; PTFE indicates the membrane PTFE-reinforcement layer; $\mathrm{An}$ and $\mathrm{Ca}$ refer to anode and cathode catalyst layer, respectively.

\section{Figures}

Fig. 1. Multi-serpentine segmented cell design: segment distributions at the (a) anode and (b) cathode side, with (c) color code for current density values ranges. The $G$ arrow represents the position of the cell in the gravitational field.

Fig. 2. Cell operation under non-humidified gas supply (approx. $5 \% \mathrm{RH}$ ). a) Development of cell voltage during the approx. $300 \mathrm{~h}$ long-term experiment at $0.7 \mathrm{~A} \mathrm{~cm}-2$ and $60{ }^{\circ} \mathrm{C}$. The inset plot shows the voltage decay in the first $5 \mathrm{~h}$. At $0 \mathrm{~h}$, the gas humidification was switched off. b) Current density plots at BoT and EoT. The colored circles indicate the segments that underwent ex-situ analyses (see Section 3.1.1 and 3.1.2). c) Cell current density evolution during the longterm experiment and d) during the first $0.5 \mathrm{~h}$ for the segments analyzed ex-situ and displayed in b).

Fig. 3 Carbon photoemission spectra of catalyst layers reveal little degradation of the fluorinated ionomer under non-humidified conditions in central (D5, comp. Fig. 1) and edge areas (I5).

Fig.4. Cell operation under water-saturated gas supply (approx. $100 \%$ RH). a) Development of cell voltage during the approx. $300 \mathrm{~h}$ long-term experiment at $0.7 \mathrm{~A} \mathrm{~cm}-2$ and $60{ }^{\circ} \mathrm{C}$. The inset plot shows the voltage decay in the first $5 \mathrm{~h}$. b) Current density plots at BoT and EoT. The colored circles indicate the segments that underwent ex-situ analyses (see Section 3.2.1 and 3.2.2). c) Cell current density evolution during the long-term experiment and d) during the first hour for the segments analyzed ex-situ and displayed in b). 
Fig. 5 Carbon photoemission spectra of catalyst layers reveal distinct ionomer defluorination under fully humidified conditions, in particular on the anode (a) and close to the gas inlet (segment I5) of the cathode (b).

Fig. 1. Change in current distribution at $700 \mathrm{~mA} \mathrm{~cm}-2(=$ EOT-BOT/BOT $* 100$ in $\%)$ due to the degradation test. Comparison between data recorded during long term test (non-humidified or fully humidified gases) and E-j curves (50\% RH) before and after test operation.

Fig.7. a) Percentage voltage loss based on E-j curves measured at BoT and EoT for the nonhumidified (black) and fully humidified (red) operated MEA. E-j curves were measured in galvanostatic mode at a cell temperature of $80{ }^{\circ} \mathrm{C}$, and under reactants humidification of $50 \%$ RH (experimental details are reported in section 2.1). b) Distribution of the relative voltage losses. For each MEA, voltage losses are shown from the three different sections of the curve in a) which correspond to activation, ohmic, and mass transport losses.

Fig. 8. Carbon photoemission spectra of microporous layer and GDL backing b) in segment I5 partial defluorination of PTFE $(292 \mathrm{eV})$ to a lower oxidation state $(<290 \mathrm{eV})$, in particular unter fully humidified conditions. 
Supplementary Materials
Click here to download Supplementary Materials: Supplementary_data_V2.docx

pemen

$\sqrt{2}$

$\sqrt{2}$
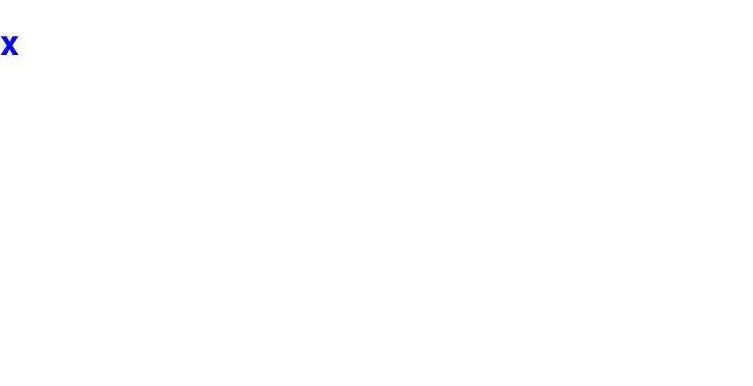